GEOLOGICAL SURVEY CIRCULAR 127

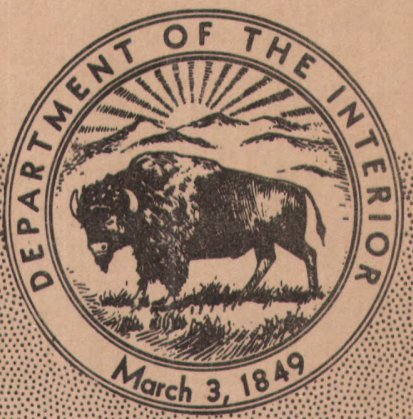

GEOCHEMICAL AND MINERALOGICAL

METHODS OF PROSPECTING

FOR MINERAL DEPOSITS

Translated from Russian by Lydia Hartsock and A. P. Pierce 



\author{
UNITED STATES DEPARTMENT OF THE INTERIOR \\ Oscar L. Chapman, Secretary \\ GEOLOGICAL S U RVEY \\ W. E. Wrather, Director
}

GEOLOGICAL SURVEY CIRCULAR 127

Academy uí Science, U. S. S. R.

\title{
GEOCHEMICAL AND MINERALOGICAL METHODS OF PROSPECTING FOR MINERAL DEPOSITS CHAPTER IV, SPECIAL METHODS OF PROSPECTING
}

By A. Ye. Fersman (with articles by S. A. Borovik, G. V. Gorshkov, S. D. Popov, and A. F. Sosedko)

Published by the Academy of Science Moscow, 1939, Leningrad

Translated from Russian by Lydia Hartsock and A. P. Pierce, U. S. Geological Survey

Washington, D. C., 1952

Free on application to the Geological Survey, Washington 25, D. C. 
Fersman's book "Geochemical and mineralogical methods of prospecting for mineral deposits" (Geokhimicheskiye i mineralogicheskiye metody poiskov poleznykh iskopayemykh) covers all petrographic, mineralogical, and geochemical techniques that are used either directly or indirectly in mineral exploration. Chapter IV is of particular interest because it describes certain geochemical methods and principles that have not been widely applied outside of the Soviet Union.

The original contained a number of photographs that have been omitted; the titles of the photographs are given in the body of the text.

Wherever possible, bibliographic references have been checked, and the full titles given. References given in footnotes in the original have been collected and added at the end of each section as a bibliography.

The transliteration of Russian letters follows the form adopted for official use by the Board on Geographic Names. This form differs from that in common usage for the following Russian letters:

Russian letter

Й

BD

Я
Transliteration

e, following a consonant

ye, at beginning of word and following a vowel or soft sign 
Introduction ..................... 1

Methods of geochemical correlation ........ 1

Methods of studying dispersion .......... 3

Secondary dispersion halos .......... 3

Saline dispersion halos ......... 3

Syngenetic salt halos....... 3

Superimposed salt halos.... 3

Mechanical dispersion halos...... 3

Syngenetic mechanical

halos .............. 4

Buried mechanical halos.... 4

Gaseous dispersion halos ........ 4

General characteristics of

secondary dispersion......... 4

Examples of studies of

secondary dispersion halos .... 5

Prospecting for salts on the lower Volga .......... 5

Prospecting for primary tin deposits ............ 5

The formation of cassiterite dispersion halos ........ 6

Primary dispersion halos........... 6

Example of a mineralogical map... 6

Kounrad copper deposit...... 6

Practical significance of Kounrad mineralogic map.. 7

The theoretical analysis of

primary dispersion halos...... 7

Combined primary and secondary halos. . 7

Appendix: Study of natural emanations of dispersed systems of solutions and salts .................. 7

References cited ................ 8

Heavy-mineral method, by S. D. Popov....... 8

Short history and significance of the study of heavy concentrates......... 8

Types of placers and the paragenesis of minerals in black sands......... 10

Methods of field investigation........ 11

The study of heavy minerals in the field

1
3
3
3
3
3
3
4
4
4
4
5
5
5

5
6
6
6
7
7
7
7
7
7
7

Heavy-mineral method, by S. D. Popov--Continued.

The separation process ............. 14

Determination of the mineral content of heavy concentrates............. 19

Determination of heavy-mineral content of the sample ............ 19

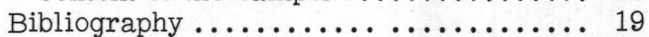

The necessary instruments and reagents for field work .......... 20

Spectroscopic methods, by S. A. Borovik..... 21 Bibliography ................. 23

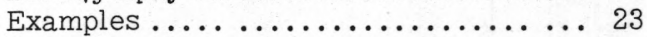

Fluorescent methods, by A. F. Sosedko, with a supplement by A. Ye. Fersman .. ... 24

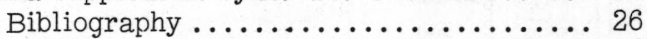

Special methods .................... 27

Prospecting based upon the study of

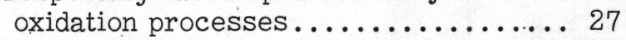

Prospecting by thermal effects....... 27

Prospecting by the chemistry of secondary processes ........... 28

Prospecting for salt deposits on the basis of secondary migration ........ 28

The use of redox, or $\mathrm{rH}$ (oxidationreduction potential).............. 28

The use of $\mathrm{pH}$ determinations ......... 28

Botanical methods ................. 29

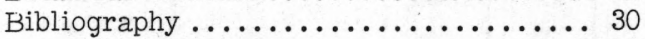

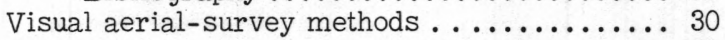

Geophysical methods of prospecting .......... 31

Bibliography ............................ 32

Radioactive methods of prospecting, by

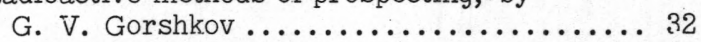

Introduction ....................... 32

Emanation method (radon and thoron).... 33

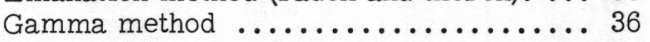

Other radioactive methods........... 37

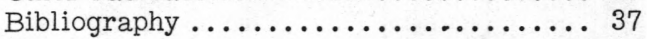

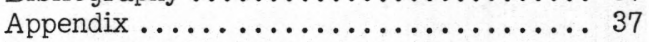

TABLES

Table 9. Gangue and country rock associated with placer deposits $\ldots \ldots \ldots \ldots \ldots \ldots \ldots \ldots \ldots \ldots \ldots \ldots$

10. Comparison of minerals of the Il'men forest preserve reported in the literature and

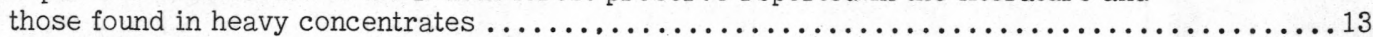

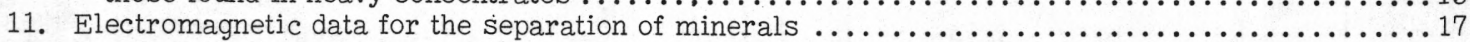

12. Spectral lines used for quantitative analysis of tin $\ldots, \ldots, \ldots, \ldots, \ldots, \ldots, \ldots, \ldots, \ldots, \ldots, \ldots, 21$

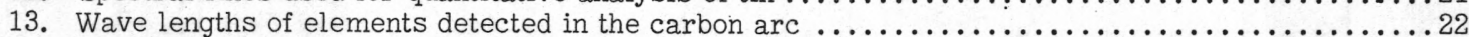

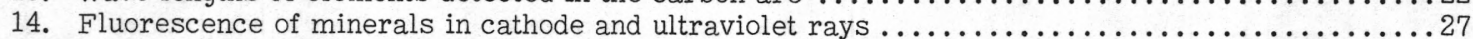

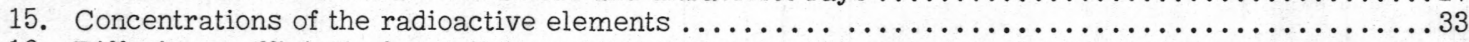

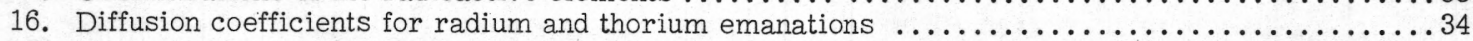

17. Concentrations of radium emanations as a function of the diffusion coefficient and

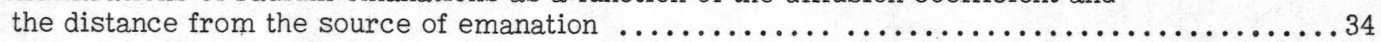





\title{
GEOCHEMICAL AND MINERALOGICAL METHODS OF PROSPECTING FOR MINERAL DEPOSITS
}

\author{
Translated from the Russian \\ Chapter IV \\ SPECIAL METHODS OF PROSPECTING
}

By A. Ye. Fersman

\section{INTRODUCTION}

This chapter contains a short discussion of the most important special methods of geochemical prospecting. These methods are extremely varied. Their development and specialization depend upon the progress of geochemical and mineralogical research. They are based on the laws of distribution of the elements in the earth's crust, in accordance with the data of V. M. Goldschmidt. Two groups of phenomena determine the paths of migration of the chemical elements. One is related to the properties of the earth's materials themselves and leads to the establishment of prospecting guides based upon the physical, chemical, and mineralogical properties of naturally occurring compounds. The other is related to environment, and the areal distribution of specific conditions which determine the accumulation or dispersion of an element. The result of the combination of these two types of factors is seen in the establishment of certain "physicochemical methods" of prospecting, whose principles have been successfully applied to salt deposits by $V$. I. Nikolayev under the partial direction of A. P. Vinogradov. V. I. Nikolayev in 1937 wrote:

"Geologic exploration for petroleum and salt deposits is usually preceded by physicochemical investigations. It should not be forgotten, however, that in the time of the celebrated van't Hoff, physicochemical studies of salt deposits had achieved considerable importance, not only in the solution of problems connected with the establishment of the character of salt deposits and their origin, but in finding means of exploiting them.

"Physicochemical studies and the application of physicochemical analysis to the solution of practical problems permit us to speak of distinct physicochemical (or more accurately, geochemical) methods of prospecting for natural resources.

"In the Kazakhstan session of the Soviet Academy of Science it was shown that chemistry, by means of its prospecting indicators, is a tool which can and does give useful data both for discovering hidden deposits and as a guide in other kinds of exploration work.

"For example the ions of potassium, bromine and boric acid may be used as indicators in prospecting for potash deposits. "

V. I. Nikolayev has shown that by means of a series of systematic analyses for potassium, bromine, and boric acid, areas of greatest concentration may be mapped, and with the aid of a diagram showing "the movements of the potassium and bromine ions with changes of geographic coordinates" one may predict the occurrence of potassium and bromine salts at depth, such as the residual salt deposits of the Permian sea. (Nikolayev, Yanat'yeva, and Polyakov, 1937, pp. 857-869; Nikolayev, Yanat'yeva, and Frishmut, 1938, pp. 345-348).

This problem has been expressed even more clearly by A. V. Kazakov (1938) in his research upon phosphorite facies and the genesis of natural phosphates. He has emphasized the importance of using a combination of paleogeographic, physicochemical, and geochemical investigations.

\section{METHODS OF GEOCHEMICAL CORRELATION}

The problems of geochemical correlation of elements and minerals are very complex as they lie at the foundation of the mineralogy and geochemistry of natural associations and paragenesis.

Every paragenesis is a definite, regular association of elements and minerals which are related by specific chemical processes. In this sense every natural association of minerals gives us a clue to the elements or minerals that can occur in the given paragenesis. Also, these associations may show the improbability of some substance being present in a particular area,

For example, it is necessary to restrict the search for lithium to associations of albite, quartz, clear beryl, and microcline, which are the paragenetic 
constituents of the geophase "F-G" 1 / in granitic pegmatites. It would be illogical and incorrect to prospect for ores of nickel and chromium in such an environment.

We will limit ourselves only to listing some typical, regular associations:

List of paragenetic associations

$$
\begin{aligned}
& \mathrm{Li}-\mathrm{Be}-\mathrm{B} \\
& \mathrm{Fe}-\mathrm{Ba}-\mathrm{Pb} \\
& \mathrm{F}-\mathrm{Al}-(\mathrm{P}) 1 / \\
& \mathrm{Mg}-\mathrm{Fe}-\mathrm{Cr}-(\mathrm{Ni}) \\
& \mathrm{P}-\mathrm{Ca}-(\text { rare earths) } \\
& \mathrm{S}-\mathrm{Heavy} \text { metals } \\
& \mathrm{S}-\mathrm{Sr}-\text { bitumen } \\
& \mathrm{Cl}-\mathrm{Na}-(\mathrm{K}, \mathrm{Rb}, \mathrm{Cs}, \mathrm{Ca}, \mathrm{Mg}) \\
& \mathrm{K}-\mathrm{Rb}-\mathrm{Cs}-(\mathrm{Li}) \\
& \mathrm{Ca}-\mathrm{Na} \\
& \mathrm{Sc}-\mathrm{Mg} \\
& \mathrm{Ti}-\mathrm{Fe}-(\mathrm{Ca}) \\
& \mathrm{V}-\mathrm{U}-\mathrm{Ra}-(\mathrm{bitumen}) \\
& \mathrm{Cr}-\mathrm{Ni}-\mathrm{Mg}-\mathrm{Fe} \\
& \mathrm{Fe}-\mathrm{Co}-\mathrm{Ni}-\mathrm{Cr} \\
& \mathrm{Co}-\mathrm{Ni}-\mathrm{Fe}-\mathrm{Mn} \\
& \mathrm{Ni}-\mathrm{Co}-\mathrm{Fe} \\
& \mathrm{Zn}-\mathrm{Cd}-\mathrm{Ga}-\mathrm{Ge}-\mathrm{In} \\
& \mathrm{Zn}-\mathrm{Pb}-\mathrm{Ag} \\
& \mathrm{As}-\mathrm{Au} \\
& \mathrm{Br}-\mathrm{Cl}-\mathrm{I}-(\mathrm{Cs}, \mathrm{Rb}) \\
& \mathrm{Rb}-\mathrm{Cs} \\
& \mathrm{Sr}-(\mathrm{SO} 4)-\mathrm{S}-\mathrm{dolomite} \\
& \mathrm{Zr}-\mathrm{Ti}-(\mathrm{Nb}, \mathrm{Ta}) \\
& \mathrm{Nb}-\mathrm{Ta}-\mathrm{Ti}-\mathrm{Zr} \\
& \mathrm{Mo}-\mathrm{W}-(\mathrm{Sn}) \\
& \mathrm{Ag}-\mathrm{Pb}-\mathrm{Co} \\
& \mathrm{Cd}-\mathrm{Zn} \\
& \mathrm{Sn}-\mathrm{W}-\mathrm{Li} \\
& \mathrm{Sb}-\mathrm{As}-\mathrm{S} \\
& \mathrm{Te}-\mathrm{Au}-\mathrm{Ag}-\mathrm{Hg} \\
& \mathrm{I}-\mathrm{Br}-\mathrm{Cl} \\
& \mathrm{Cs}-\mathrm{Rb}-(\mathrm{Li}) \\
& \mathrm{Ba}-(\mathrm{SO} \text { ) }-(\mathrm{Pb}) \\
& \mathrm{W}-\mathrm{Sn}-(\mathrm{Au}) \\
& \mathrm{Au}-\mathrm{Ag}-\mathrm{As}-(\mathrm{Te}) \\
& \mathrm{Hg}-\mathrm{As}-\mathrm{Sb} \\
& \mathrm{Pb}-(\mathrm{Zn}) \\
& \mathrm{Th}-\mathrm{rare} \text { earths } \\
& \mathrm{U}-\mathrm{Ra}-(\mathrm{V}, \mathrm{As}, \mathrm{P}) \\
&
\end{aligned}
$$

1/ The parenthesis are reproduced as given in the original; no explanation was given as to their significance.

In addition to the correlations of elements resulting from the general laws of geochemical association, we have a number of special rules, which may be applied under certain circumstances. For example a number of authors have noted interesting correlations with the different degrees of oxidation of vanadium: $V^{+5}$ is associated with bitumen, and $\mathrm{V}^{+3}$ with the primary silicates. Thus in prospecting for petroleum an increased $\mathrm{V}^{+5}$ : $\mathrm{V}^{+3}$ ratio indicates an increased concentration of bitumen in the rock. (Baturin, 1938)

${ }^{1}$ Translators' note: geophase F-G represents the temperature range between $400^{\circ}$ and $500^{\circ}$ C. See Fersman, A. Ye., Pegmatity, vol. 1, Chap. 4, pp. $37-39,1940$.
A particularly interesting example is the use of strontium correlations as a prospecting indicator in the European part of the U. S. S. R. and in the Ural Mountains. Celestite, gypsum, rock salt, anhydrite, and copper compounds are the most characteristic minerals of the marine Permian beds. V. I. Nickolayev has drawn attention to the fact that there is a marked difference between the composition of the Caspian Sea and its deposits, and the probable composition of the Permian sea and its deposits (Nikolayev and Kalinin, 1938). This can be seen from the large concentrations of sodium chloride in the Permian sediments as compared to the accumulation of magnesium and calcium sulphates in Caspian sediments. The hypothesis that some orderly process led to a greater concentration of strontium sulphate. in the Permian sediments as compared to the Caspian sediments is confirmed by a number of analyses. In view of this the following conclusion by Nikoloyev appears to be entirely logical:

"We can now regard the strontium ion as a new prospecting indicator, which like $\mathrm{K}$ or $\mathrm{Br}$ may be used to establish the genesis of salt deposits and natural waters, and to differentiate between Caspian and Permian salt deposits. Concentrations greater than 0.02 percent Sr are characteristic of Permian salt deposits, while concentrations that do not exceed 0.01-0.02 percent may be regarded as typical of Caspian deposits.

"Basins of purely Caspian origin, such as Ozero Balkhash, are characterized by Sr concentrations in the order of thousandths of a percent, while the $\mathrm{Sr}$ concentrations of the brines and springs of Ozero Inder range from 0.02 to 0.08 percent $\mathrm{Sr}$, which immediately shows a connection with Permian salt deposits."

There is little doubt that as the result of further investigations in different regions, other elements may become important as prospecting indicators.

On the basis of the examples given above we may define the idea of geochemical correlation as follows:

We generally understand correlation to be the method of comparing sedimentary rocks according to their preferential associations (this would also apply to magmatic and metamorphic rocks). In particular, however, we will define a geochemical correlation to be one which is based upon the methods of comparing the concentrations of different chemical elements.

The use of specific chemical features for tracing the continuity of sedimentary layers in complex formations is of great interest and is being constantly applied by various scientists, especially in the Soviet Union (Ya. V. Samoylov: "On the principle chemical elements analogous to the principle minerals", 1913; A. F. Fioletova: in a number of interesting articles on clays, 1925-1929; A. Vezir-Zade and M. Mirchink: "The experimental correlation of petroleum-bearing beds according to the carbon coefficient. "; and so on). 2/ The large volume of accumulated information does not allow us to generalize as yet with regard to this very. complex question, as we do not possess enough

${ }^{2}$ In the foreign literature upon geochemical correlation may be noted, for example, the work of Leith and Meade, and others. 
systematic analyses of complete sedimentary suites, either in vertical or horizontal cross section.

Nevertheless this method deserves the attention of stratigraphers, especially in the study of coal and petroleum deposits. We hope that there will be additional excellent research such as the correlation of petroliferous rocks of the Apsheronskiy Poluostrov [Apersheron Peninsula] by means of petrographic and mineralogical indicators (Baturin and Gubkov, 1929).

As an example here, I wish to cite the very interesting research of $\mathrm{V}$. Levinson and A. Kocharev (1930) who developed the idea of stratigraphic correlation by means of the concentration and degree of oxidation of vanadium. The authors proceeded from the laws of the geochemical distribution of $\mathrm{V}_{2} \mathrm{O}_{3}$ and $\mathrm{V}_{2} \mathrm{O}_{5}$ in rocks, by which the former is related to silicate systems of primary origin, whereas the second is related to organic matter. Thus, $\mathrm{V}_{2} \mathrm{O}_{3}$, which is highly dispersed, may be used for correlations, which $\mathrm{V}_{2} \mathrm{O}_{5}$ indicates the bitumen content of rocks.

\section{METHODS OF STUDYING DISPERSION}

The above example of the roles that strontium, boron, and bromine play as prospecting indicators shows us that the types of distribution and dispersion of some elements are of interest to the prospector.

Dispersion can be divided genetically into two types. One type is of a secondary character and is the result of the mechanical and chemical dispersion of previously formed deposits. The other type is a primary dispersion pattern of the given element or substance. The problem is to find a method for locating places of concentration within the primary phases on the basis of the fundamental laws of geochemical distribution.

\section{Secondary Dispersion Halos}

determined by the geochemical and geoenergetic sic properties of the given compounds.

: On the basic of a number of experiments N. I. Sofronov (1936) has come to the following conclusions:

The term "dispersion halo" of a mineral deposit may be defined as that zone of "eluvium-deluvium" [see "deluvial placers" p. 10 ] (in some cases alluvium) which has been enriched by a characteristic element derived from a primary deposit without regard for the state of aggregation of the element. The term embraces the areal aspects of the pattern, and the processes by which the mineral deposit passes from. a state of concentration to a state of secondary dispersion.

The principal agents causing the formation of dispersion halos are those of supergene surface weathering.

Halos may be classified first according to the dispersed element under consideration, and also according to the origin of the halo with due regard for the transient state of the eluvium-deluvium and of the dispersed phase.

\section{Saline Dispersion Halos}

In saline halos the indicator element occurs as recently deposited material, usually as a soluble salt in the weathering zone, such as a sulfate.

The laws for the formation of these halos involve both chemical and physical principles.

Saline halos characteristically form in the weathering zone of deposits, such as polymetallic sulfide deposits. A schematic diagram showing the typical evolution of the halo of a sulfide deposit follows:

The dispersion of elements and minerals in sands and placer deposits is confined to definite areas

\begin{tabular}{|c|c|}
\hline $\begin{array}{l}\text { Country rock }+ \\
\text { weathering agents. }\end{array}$ & $\begin{array}{l}\text { Mineral } \\
\text { absorbing } \\
\text { complex. }\end{array}$ \\
\hline $\begin{array}{l}\text { Primary sulfides + } \\
\text { weathering agents. }\end{array}$ & $\begin{array}{c}\text { Electrolytic } \\
\text { solutions } \\
\text { (chiefly sulfates) }\end{array}$ \\
\hline
\end{tabular}

Saline dispersion halos

Phenomena causing the evolution and fixation:

1. Coagulation of the colloids of the absorbing complex by

electrolytes.

2. Diffusion and capillary ascent.

3. Adsorption of the electrolytes by absorbing complexes through diffusion and capillary ascent.
From the viewpoint of genesis we may differentiate between the following:

Syngenetic salt halos. --T'he absorbing complex is represented by eluvium-deluvium which has been formed simultaneously with the electrolytes. Coagulation of the colloids of the absorbing complex by the cations of the electrolytes is most important during the evolution and fixation of the halo. Later, the principal role is played by diffusion and capillary action accompanied by adsorption of the cations.

Superimposed salt halos. --The absorbing complex is represented by alluvium; solutions more recent than the mantle are formed. Capillary action and diffusion accompanied by adsorption of the cations are most important in the evolution and fixation of the halo. These halos are less easily reached in surface prospecting.

\section{Mechanical Dispersion Halos}

The indicator elements of mechanical dispersion halos will be found in the form of primary minerals which are stable in the weathering zone.

The laws for the formation of the halos are both physical and physiochemical. 
Mechanical halos are characteristic of those deposits which are composed of stable minerals occurring within the weathering zone, such as deposits containing cassiterite, wolframite, chromite, native gold, molybdenite, and others (Andreyev, 1931).

\begin{tabular}{|c|c|}
\hline $\begin{array}{l}\text { Country rock + } \\
\text { weathering agents. }\end{array}$ & $\begin{array}{l}\text { Reduction in volume } \\
\text { of eluvium-deluvium } \\
\text { layers. }\end{array}$ \\
\hline $\begin{array}{c}\text { Quartz-cassiterite } \\
\text { vein. }\end{array}$ & $\begin{array}{l}\text { Friable vein material } \\
\text { without loss, }\end{array}$ \\
\hline
\end{tabular}

A schematic diagram of the evolution of a typical mechanical halo from a quartz-cassiterite deposit may be presented as follows:

$$
\cdot \cdot x^{2}
$$

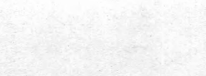

Besides the conditions necessary for the formation of mechanical halos we wish to add the following:

Ore minerals may be released during weathering from the wall rocks of the vein where the minerals usually occur either as disseminated crystals or in small stringers which are associated with the principal vein. The release of these materials tends to intensify the halo.

A marginal drift or general creep of the eluviumdiluvium may result in deformation of the halo.

From the viewpoint of genesis the following classifications can be made:

Syngenetic mechanical halos. --The weathering of the country rock produces eluvium-diluvium with the vein simultaneously contributing particles of ore materials. This type of halo is the most important in prospecting.

Buried mechanical halos. --The overlying rocks are alluvial and have been transported from a distance. The halo was formed earlier or is formed under the alluvium. From the standpoint of prospecting, these halos present a more difficult problem.

\section{Gaseous Dispersion Halos}

In this type of halo (Chikrysov, 1938, pp. 62-64) the indicator element occurs in the gaseous phase. The laws of the formation of these halos are chemical, physicochemical, and physical. Gaseous halos are especially characteristic of deposits containing gas either as the economic product (as in a helium deposit), as a natural by-product (as in a petroleum deposit), or as the product of the radioactive decay of primary material (radium-uranium and thorium deposits).

A schematic diagram of the formation of a gaseous halo would show how gaseous products are distributed by diffusion within primary rocks from which they enter the eluvium, or are taken up by water in the form of characteristic solutions.

From the genetic viewpoint the gaseous halos associated with oil pools are obviously of the superimposed type, whereas the halos associated with radioactive deposits are syngenetic.
General Characteristics of Secondary Dispersion

The interesting ideas of N. I. Sofronov presented above undoubtedly deserve attention, but need a more detailed development with regard to the particular geochemical processes.

We may assume that mechanical dispersion halos depend upon the value of the "ek" $3 /$ and the combining energy of the lattice since the higher the combining energy of the lattice, the greater the stability and the larger the radius of dispersion of the primary mineral.

A deviation from this rule results from the mechanical properties of minerals, such as where the friability of a mineral causes it to be readily pulverized.

It is interesting to note that the size of a saline halo is related to the type of absorption and the degree of polarization of the ions. The latter is especially critical and undoubtedly determines the extent of absorption and type of coagulation (according to W. Noll).

Naturally, the practical application of the theory of halos must be studied and proved in detail. In saline halos associated with sulfide deposits the concentration of sulfate ion may be traced within areas of contrasting supergene processes. For mechanical halos the minerals can be arranged in the order of diminishing size of halo. The figures after the minerals in the following list give the mean "paragens" by my computations.

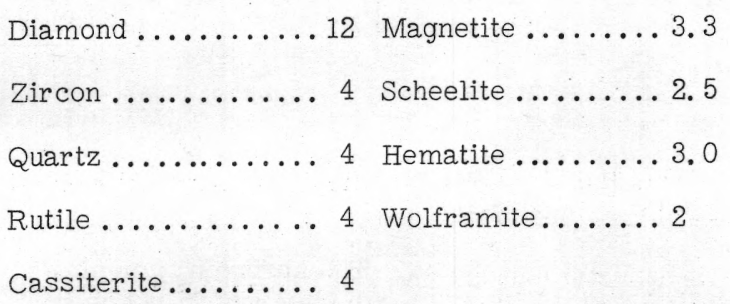

'Translators' note: In Fersman, A. E., The periodic system of energy coefficients (in English): Acad. Sci. U. R. S. S., Comptes rendus, v. 3, pp. 173-176, 1935, the "ek" is defined "as the amount of energy which an ion of definite valency existing in infinity contributes on passing into $w^{a}$ system of a heterpolar crystal lattice." It is numerically equal to $K{ }_{2} w^{2}$ where $K=$ constant, $w=$ valence, $R=$ ionic radius. 
Note that this series decreases from left to right in the same order as the mean "eks" and "veks" of the cations. Further research into this problem will, undoubtedly, clarify the situation and yield more accurate methods of locating halos on the basis of the concept of paragens, and confirm the figures for distance of migration for different minerals.

\section{Examples of Studies of Secondary Dispersion Halos}

Prospecting for. salts on the lower Volga.--An excellent example of the methods of geochemical prospecting is furnished by the work of a salt-prospecting expedition in the Primorsk district, Kalmyk A.S.S.R., 1937 (Nikolayev, Yanat'yeva, and Polyakov, 1937, pp. 857-869; Nikolayev, Yanat'yeva, and Frishmut, 1938, pp. 345-348). Samples were collected and quantitatively analyzed from twenty drill holes and shallow pits. The results show not only a variable concentration of bromine and particularly boron, but higher concentrations as compared with the waters of the Caspian Sea. A high concentration of boric acid ( 0.9 percent) was found in deep drill holes (as much as $200 \mathrm{~m}$ ), and also in shallow pits.

"By plotting on a map points, which clearly showed an increased concentration of potassium, bromine, and boric acid in the waters, two areas in the Primorsk district were indicated where the presence of both potash and borate deposits may be expected at depth. Specifically, the data of this physicochemical survey indicate that the area around and to the northwest of the Ulan-Tug state farm, and also the area between Olenichev and the river Ulan-Khol are most favorable for the discovery of potash and borate deposits.

"With regard to the question of why the waters of springs and artesian wells accumulate such large quantities of boric acid we may tentatively assume that there is a washing out of the borate deposits at depth by waters that are rich in magnesium sulfate. All the lakes in the Primorsk region have high concentrations of magnesium sulfate in their brines. " Thus, by the application of geochemical methods, maps were made of the areas containing the highest concentrations of bromine, boron and potassium salts at depth.

Prospecting for primary tin deposits. --Soviet scientists have worked out excellent methods for prospecting for primary tin deposits by means of dispersed deposits (Ozerov, 1937; Flerov, 1935; and 1938; Sarkisyan, 1939). The following is an excerpt from the interesting work of B. L. Flerov:

"The distance of transport of cassiterite from the primary deposit depends chiefly upon the longitudinal profile of the valley. The greater the grade of the river bed, the greater will be the strength of the current, which determines the size and weight of the transported particles. In regions of active vertical erosion, for example, Verkhoyansk and Kolyma districts, the steep grade of the valley prevents the friable cassiterite, which has a lower specific gravity than gold, from accumulating in large placer deposits. The larger part of it is transported to considerable distances and is dispersed. Deposits formed in areas of more gentle relief, like Transbaikal, undoubtedly would contain sands of economic value. Naturally, favorable conditions for deposition are locally possible in mining districts, and consequently cassiterite placers may occur in these regions, especially in the vicinity of coarse fragments of cassiterite.

"The formation of placer deposits depends upon the manner in which the cassiterite is distributed in the ore-bearing rock and the composition of the rock. The more coarse the segregations of cassiterite or its individual particles, the more concentrated and closer to the original deposit will be the placer deposit. The formation of a placer deposit is favored by an erratic distribution of cassiterite in the vein, whereby coarse fragments of high specific gravity are found. On the other hand finely disseminated cassiterite will be transported further both because of its small size and because its separation from the gangue occurs during transport over a greater distance. Sulfide veins with microdisseminated cassiterite as a rule do not yield productive deposits.

"The vein minerals must be resistant to produce the large segregations that result in concentrated deposits. If the vein material is easily weathered there will be no cohesion in the cassiterite segregations and they will break up into small particles. Cassiterite disseminations associated with resistant minerals will break up during long term transportation and result in scattered deposits. In this case it is better if the cassiterite is disseminated within softer minerals from which it will separate more quickly. However, if the vein minerals are too soft this will lead to a grinding up of the cassiterite already in the deluvium.

"Minerals associated with cassiterite will not serve as independent prospecting indicators. In most deposits cassiterite occurs in sufficient quantities so that if it occurs in the primary deposit it will be found in the sediments. Sulfide veins with microdisseminations of cassiterite are the only exceptions to this rule. In this case the sulfires or their alteration products are prospecting indicators, even though the tin is high grade.

"The heavy mineral associations in alluvium may give indications as to the type of deposit. The association of cassiterite with sulfides indicates hydrothermal deposits. An association with topaz indicates pneumatolytic deposits. An association with the tantalo-niobates indicates a pegmatite deposit. Clear, needle-like tourmaline is very characteristic of deposits that are transitional from hydrothermal to pneumatolytic. Dark tourmaline is usually a negative indicator because it is formed at an earlier stage than cassiterite. Green chlorite is often associated with cassiterite in the northeast part of the U. S. S. R., and seems to take the place of tourmaline in deposits free of boron emanations. The association of cassiterite with albite, orthoclase and muscovite may point to pegmatitic as well as pneumatolytic types of deposits. If the cassiterite is associated with adularia it indicates a hydrothermal deposit. Wolframite and scheelite are frequently associated with cassiterite in deposits of the transitional type, but most often these minerals occur separately and are not characteristic.

"Gold is frequently associated with cassiterite in the sediments of some regions, but it is usually not derived from the vicinity of the primary cassiterite 
deposit. However, these minerals may occur together in sulfide deposits and under some hypabyssal conditions.

"The crystal form of cassiterite may also be an indication of the type of primary deposit. (See page 382) [not translated]

"The formation of cassiterite dispersion halos. -During the weathering of the primary ore body, part of the cassiterite breaks loose directly from the outcrop of the vein, another part is separated from blorks as they move down the slope, and a third part reaches the bottom of the slope in the form of aggregates of cassiterite and gangue. The cassiterite freed from other vein material moves down the slope with the deluvium, and under the influence of gravitaticnal differentiation is concentrated in its lower layers.

"The more gentle the slope and the greater the amount of deluvium, the deeper is the enriched layer. The depth to which it settles also depends upon the type of deluvium. One often sees slopes covered with fragmental material or granitic gravels. Cassiterite can easily settle through these loose layers and reich the more compact layers of deluvium, or even bedrock. The most favorable materials for the concentration of cassiterite appear to be dense clayey sands or clayey detrital material. We have noticed that cassiterite is founc near the top of such materials. Cassiterite may also be found in small fragments which have low specific gravity and occur higher in the deluvium than the grnins of cassiterite. Pulverized cassiterite will rise into the upper layers of the deluvium, except, of course, the humus. By the author's observations the thickness of such enriched layers reaches several tens of centimeters.

"The schematic diagram of the dispersion halo takes the shape of a fan, widening slightly toward the bottom. Owing to the dispersion of the cassiterite within the mass of the diluvium, its concentration in the halo is of course smaller than in the source rocks and diminishestowards the edges of the halo. The greater concentration of cassiterite will be found next to the vein where the amount of dilution of the vein material has been insignificant. At this place the enriched layer of the deluvium merges into the primary rock.

"A 0.01 percent concentration of tin in the halo is a good indication for prospecting. According to the data of the Geophysics Branch of Central ScientificResearch Geological-Prospecting Institute, the width of a typical enriched halo is from 25 to 30 meters measured perpendicular to the vein."

On the basis of his work in Transbaikal, S. G. Sarkisyan states that cassiterite disintegrates quickly, and does not resist transportation for distances greater than from 0.5 to 2 kilometers from the primary deposit.

\section{Primary Dispersion Halos}

The establishment of favorable loci for the concentration of any mineral or chemical element is related to processes of precipitation of solid matter from more dispersed fluid or gaseous systems. Certain definite conditions of temperature, pressure, and wall-rock composition must prevail before crystallization can begin. Furthermore, such precipitation occurs over a definite time and area (the halo, or more accurately the areal dispersion pattern of a given compound). High concentrations of material occur only locally, and are surrounded by primary dispersion halos. It is interesting that Elie de Beaumont in 1847 spoke of primary halos of elements distributed about granite masses, calling them "aura granitica". This is true of chromite, magnetite, and titanomagnetite ores deposited at lower temperatures. Because the sites of highest concentration are surrounded by zones of progressively dispersed ore material, the making of an accurate survey of the dispersion halo may lead to the location of the center of mineralization. This is done by plotting isograds (lines of equal concentration) of the given substance or element to discover the direction of increasing concentration and the areas of greatest enrichment. The Americans in particular have used this method to a large extent, naming it according to the nature of the metal, as: cuprometric or stannometric. It is based upon systematic analyses for the given element in samples collected on both horizontal and vertical grids. The areas of highest concentration can then be plotted in three dimensions. Frequently this method is called "geometrical." See chapter on mapping page 144 [not translated].

Such methods of geochemical mapping are of great importance in prospecting and in the solution of theoretical problems (methods of the Chinese scientists, Shu and Li). However, results of systematic sampling and the compilation of geochemical maps may be further enhanced by compiling "mineralogical maps". These are diagrams of the distribution of minerals rather than chemical elements on a three dimensional grid. Ya. D. Gotman (1936, pp. 1-64) has given us an excellent example of such maps in his mineralogical analysis of the Kounrad deposits.

\section{Example of a Mineralogical Map}

Kounrad copper deposit. --The mineralogical map of the Kounrad porphyritic copper deposits is the first attempt at compiling a map of this type.

Such a map is the result of systematic mineralogical sampling and should form the basis for orerecovery studies. Therefore such maps should be part of the survey of every mineral deposit.

In Kounrad where the ore mineral is distributed throughout the rock quite uniformly as compared with other types of deposits; random-sampling methods are justified.

In other types of mineral deposits, such as veins and mantos where the distribution of the ore minerals in the rock is extremely variable and the thickness of the ore bodies is small, the method of random sampling must be replaced by a method of systematic sampling. Samples are collected a-meter apart and broken up. (Core samples or bores from prospecting pits or shafts may be collected.). A typical sample is polished and athin-section is prepared for analysis. Mineralogical analysis of crushed ores is described in detail in an article by A. A. Glagolev and Ya. D. Gotman, (1934). 
The bulk-sampling method may be applied to porphyritic and stockwork types of ore deposits when it is desirable to obtain the exact content of a metal or mineral within a particular zone or horizon, or in a deposit of small areal extent.

Therefore, the use of the mineralogic method of sampling depends on the structure of the mineral deposit, its thickness and the distribution of ore minerals.

The mineralogical map is not only of practical importance but also has considerable theoretical importance in solving questions of the origin of mineral deposits. Although such a map does not supply complete information regarding the genesis of mineral deposits, it does provide good supplementary information on the history of the formation of a mineral deposit.

Practical significance of Kounrad mineralogic map. ---Mineral distribution charts plotted on horizontal and vertical sections of the ore deposits show the distribution of the ore and the principal non-ore minerals in the central Kounrad area. (Malachite, azurite, covellite, chalcopyrite, chalcocite, andalusite, quartz and others have been plotted).

The outstanding parts of the mineral deposit, in which there has been great industrial development, has a zone of oxidation in contrast with other areas where this zone is absent.

Within the boundaries of sulfide zone, the enriched and the impoverished areas may be distinguished.

In compiling the map, examinations were made of 4000 polished sections and of 100 thin sections, representing samples from 25 drill holes.

The author reaches the following completely accurate conclusion: In mining ores with a low metal content, such as porphyritic ores, special methods of treatment are used. The smelting process which is profitable for high-grade ores gives way to a combination of smelting preceded by concentration, which is in most cases a physical or physicochemical process, depending on the properties of the ore minerals.

Therefore, in concentrating ores one should be familiar with the quantitative mineral composition of the ore, as well as the properties of these minerals, inasmuch as differing properties of the minerals make it necessary to use different methods of concentration on ores from different deposits.

\section{The Theoretical Analysis of} Primary Dispersion Halos

Geochemical analysis (Fersman, 1937, p. 451) helps to make clear the processes of dispersion and indicates those types of atoms and compounds which possess the highest mobilities and which occur most frequently in large halos. A detailed discussion of this subject may be found on page 40 (Chapter I) [not translated 1. Compounds with ions of large radii and small energetic coefficients (eks and veks) should have the highest mobilities; that is, ions of low valence, and complex molecular ions with large radii. Examples are: Cs - a univalent cation, with the lowest ek and vek for cations $(0.30)$, and with a very large radius
(1. $65 \AA)$; and $\left(\mathrm{NO}_{3}\right)$ - a univalent anion, with a very small ek and vek $(0.19)$, and a radius of $2.57 \AA$.

As a result of these relationships, I have set up the equation $D=\frac{R}{W}$, which gives the relative mobility of the ion, and its maximum dispersion away from the primary magmatic nuclei. As an example, $D$ for $\mathrm{Na}=0.98$ and $D$ for $\mathrm{Cs}=1.65$; in the metallic group: $D$ for zinc $=0.21$ and $D$ for cadmium $=0.26$. A more detailed and exhaustive study of this constant is necessary.

\section{Combined Primary and Secondary Halos}

Guided by the principles of primary and secondary dispersion of elements, we can better study regions where a general deficiency or abundance of a particular element exists. Regions that are deficient or rich in certain elements have been studied in detail from the economic, medical and geochemical point of view by A. P. Vinogradov. For our purposes, we are chiefly interested in high clarke values 4 / in a qive area. For example, a positive clarke value for mercury, iron or lithium will reveal an area of enrichment as a guide to exploration. By a positive clarke we mean concentrations which are greater than the average clarke of the earth's crust; negative ones are those that are below the average clarke value, On the other hand, negative values should be taken into consideration in making a thorough geochemical survey; for instance, a deficiency of sulfate ions in water may indicate the presence of petroleum or coal, or may reveal concentrations of radium and mesothorium in the water. A low concentration of calcium and magnesium in water, especially in petroleum districts, may point toward increased concentrations of boron salts, or other salts.

\section{Appendix}

\section{Study of Natural Emanations of Dispersed Systems of Solutions and Salts.}

Minerals are defined as those compounds which are relatively stable and are fixed in stable crystalline systems with the largest entropy and the highest symmetry. However, geochemical processes are not limited to these ultimate products of chemical processes; in intermediate circumstances, we may expect a more complex picture of solutions and gases than is seen in solid materials. With regard totitanium account must be taken of the transient compounds, $\mathrm{TiF}_{4}$ and $\mathrm{TiCl}_{4}$, which are very important in the migration of titanium. Therefore, the study of transient minerals of the geochemistry and mineralogy of temporary gaseous or liquid systems, may be of great value in prospecting.

This idea brings to mind the early studies of gaseous emanations, begun so brilliantly by Elie de Beaumont, and continued by LaCroix, Zambonini, Karobbi, and Vernadskiy and which achieved remarkable results in the work of the Carnegie Geophysics Laboratory in Alaska (Katmai). It is important that similar investigations be made in Kamchatka and in the Caucasus.

4Translators' note: The word "clarke", introduced by the Russians in honor of F. W. Clarke, author of the Data of Geochemistry, means the average content of a given element in naturally occurring material. When unqualified, it usually refers to the earth's crust. 
In the same manner we have a problem in the study of mineral waters, juvenile as well as vadose, which are interesting not only for their chemical properties but also for their characteristic associations.

Following this lead (V. Vernadskiy), we may obtain a completely new concept of the course of geochemical processes. The study of the composition of solutions and gaseous emanations may reveal guides in prospecting for valuable minerals, especially rare metals.

\section{References Cited}

Andreyev, B. A., 1931, Tsentral'. nauchno-issledov. geol. -razved. inst., no. 10, p. 34.

Baturin, V. P., 1938, Fluorite in the Kurgurian limestones and dolomites of the Ural-Emba region: Acad. Sci. URSS. Comptes rendus, no. 6-7, pp. 503-506.

Baturin, V. P., and Gubkov, P., 1929, Mikropetrograficheskiy metody parallelizatsii neftyanykh otlezheniy [ Micropetrographic method of correlating petroleum deposits 1: Azerbaydzh. neft. khoz., no. $6-7$, p. 10 .

Chikryzov, G. S., 1938, Gazovaya s"yemka [Gas survey 1: Razvedka nedr, no. 7, pp. 62-64.

Fersman, A. Ye., 1937, Geokhimiya, vol. 3, pp. $321-350$.

Flerov, B. L., 1935, Primeneniye olovometricheskoy s"yemki pri poiskakh korennykh mestorozhdeniy olova [Application of the stannometric survey to the exploration of primary tin deposits 1: Redkiye metally, no. 1.

1938, K metodike poiskov' korennykh olova [On methods of prospecting for primary tin deposits ]: Sov. geologiya, v. 8, no. 10, pp. 63-81.

Gagolev, A. A., and Gotman, Ya. D., 1934, Kolichestvennyy mineral-ogicheskiy analiz droblenykh rud [Quantitative mineralogical analysis of crushed ores 1: Min. Syr'ye, no. 3.

Gotman, Ya. D., 1936, Mineralogicheskaya karta Kounrada i metodika yeye sostavleniya [ The Kounrad mineralogical map and the methods of its compilation 1: Vses. inst. min. syr'ya, no. 97, pp. 1-64.

Kazakov, A. V., 1938, Fosforitnye fatsii i genezis prirodnykh fosfatov [Phosphorite facies and the genesis of natural phosphates 1: Sov. geologiya, vol. 8, no. 6, pp. 34-47.

Levinson, V., and Kochkarev, A., 1930, Nekotorye voprosy neftyanoy geologii i redkiye elementy [Some problems of petroleum geology and rare elements 1: Azerbaydzhan. neft. khoz., no. 7-8. pp. 74-89.

Nikolayev, V. I., and Kalinin, S. K., 1938, Strontsiy kak odin iz khimicheskikh poiskovykh priznakov [Strontium as a geochemical prospecting indicator ]: Akad. Nauk SSSR Doklady, new ser., tom 20, no. 6, pp. $465-466$.

Nikolayev, V. I., Yanat'yeva, O. K., and Frishmut, M. A., 1938, Fiziko-khimicheskaya razvedka 1937g. v Primorskom rayone Kalmytskoy ASSR [Physicochemical survey of 1937 in the Primorsk region of the Kalymyk A. S. S. R. 1: Akad, Nauk SSSR Doklady, tom 18, no 6, pp. 345-348.

Nikolayev, V. I., Yanat'yeva, O. K., and Polyakov, V. D., 1937, Fiziko-khimicheskaya kharakteristika rayonov solyanykh kupolov Stalingradskogo kraya i Kalmykii [Physicochemical characteristics of the salt dome districts of the Stalingrad region and
Kalmyk]: Akad. Nauk SSSR Izv. , ser. khim. ; no. 4, pp. 857-869.

Ozerov, P. M., 1937, Stannometricheskaya s"yemka kak poiskovyy metod [Stannometric method as a prospecting method 1: Razvedka nedr, no. 24, pp. 52-56.

Sarkisyan, S. G., 1939, Petrografiya rykhlykh kassiteritsoderzhashchikh otlozheniy Zabaykal'ya [The petrography of the cassiterite-bearing deposits of Transbaikal], thesis and dissertation, Moscow.

Sofronov, N. I., 1936, K voprosy ob oreolakh rasseyaniya [On the problem of dispersion halos]: Probl. sov. geologiya, no. 4, pp. 302-323.

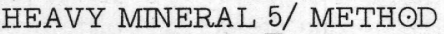 By S. D. Popov}

\section{Short History and Significance of the Study of Heavy Concentrates}

The Americans were pioneers in the study of mineral products found in alluvial deposits, especially in the heavy residues separated by washing--the socalled heavy concentrates.. In 1853, Blake studied heavy minerals from sedimentary sands on the shores of the Pacific Ocean, where he found that the black sand contained from one to three tenths as much platinum as gold. In 1873, Silliman studied not only gold and platinum in heavy concentrates, but also other minerals, such as chromite, magnetite, zircon, rutile, garnet, diamonds, topaz, pyrite, and others. A systematic study of black sands in the United States was begun in 1905, when Congress authorized the Geological Survey to investigate thoroughly the sands on the shores of the Pacific Ocean and in other parts of the United States. The principal object of this investigation was to examine the mineralogical content of deposits of grey and black sands, as well as the possibility of their commercial utilization. This study of black sands in the United States has permitted the American scientists Robert Richards, David Day, H. Milner, C. Raeburn and others to work out detailed techniques for investigating heavy-mineral concentrates, such as methods of identifying the rare earth minerals, heavy minerals, field procedures, and sampling techniques. For the separation of black sands into their constituent minerals, special concentration plants equipped with the latest technical devices were developed, which enabled American commercial organizations to obtain nearly pure concentrates of wolframite, scheelite, cassiterite, zircon, and others. The Americans were thus in a position to develop practical uses for the products from black sands.

Other countries were also recovering minerals from black and grey sands. For instance, English companies obtained diamonds from the alluvial deposits of Brazil; Japan concentrated magnetic sands, although these did not provide sufficient raw materials for the domestic steel industry

In Czarist Russia, where the industrialization of the country as well as the development of ferrous and nonferrous metallurgy was not given sufficient attention, and where the wealth of a few individuals was

\footnotetext{
"Translators' note: the Russian word "shlikh" has no exact English equivalent. It has been variously translated as heavy mineral, heavy concentrate, black sand.
} 
more important than the development of the country, it was natural that such techniques as the study of heavy minerals in prospecting were not used, and that there was no extraction of magnetic iron ore and other products from placers. It is true that some scientists connected with mining tried to direct the attention of miners toward the possibility of utilizing black sands commercially. But, since science in Russia at that time was at a low level of development, and this field did not promise great profit, the problem did not receive attention. In the last century, Ye. A. Taube and Abikh pointed out the possibility of exploiting the black magnetic sands along the coasts of the Black Sea for the needs of the Kerch metallurgical works. They also directed attention to the large deposits of magnetic sands along the seashores near Batum. K. I. Lisitsin noted the dark sands in the shores of the Azovskoye More [Sea of Azov], which according to the investigations of.P. N. Chirvinskiy contained from 25.19 to 64.52 percent mägnetite.

The recovery of magnetic iron from the black sands was not only attracting attention, but during the period of the imperialistic war, the question of processing rutile-bearing sands was raised. In Transbaikal in 1915, K. K. Matveyev investigated sands in which he found from 1.2 to 55 percent $\mathrm{TiO}_{2}$. The search for rutile also attracted attention to the monazite content of the sands.

In this way, the problem of studying the mineralogical content of black sands and the method of separating them into their components became important. But the low level of Czarist science, inertia in working out the methods, and the absence of funds for scientific research, were a hindrance to the development of the studies of heavy mineral concentrates. However, in the Soviet State, a country conquered by the proletariat, the opportunities for placing scientific research on the highest level are great, and in this manner the wealth, hidden in the earth, is put at the disposal of liberated humanity.

Each year the geological organizations send out many parties to explore for the needed nonferrous metals. But these explorations do not always bring satisfactory results. One of the reasons for this is the fact that the exploring parties are not sufficiently interested in the collection of black sands. In prospecting for rare minerals, especially in regions where outcrops are scarce, the heavy-mineral method is of great value. Using this as a reconnaissance-exploration method, we remove an element of uncertainty at a stage when the discovery of mineral deposits by geological methods is necessarily haphazard. This is why the heavy-mineral method has been of such great importance during the last five or six years.

In the Soviet Union, the principles of heavymineral prospecting were established in 1927 at the initiative of the senior geologists of Central Scientificresearch Geoiogic-prospecting Institute, S. S. Smirnov and others, who, in introducing the problem, endeavored to establish the necessity for compiling heavy-mineral maps as a starting point in prospecting. But in the process of practical work it was apparent that heavymineral analysis not only formed a basis for exploration, but also put the question to the gold industry and to scientific research institutions, that heavy minerals from placer deposits might be utilized in industry.
In the gold placer and in black-sand deposits sampled by parties prospecting for nonferrous metals and rare earth elements, other minerals have often been found, which, in addition to the more abundant elements, could doubtlessly be used in industry. These minerals include: scheelite, wolframite, cassiterite, monazite, columbite, tantalite, zircon and others. Their abundance in black sands deserves the attention of the nonferrous and rare-elements industries.

\section{As early as 1932, A. Ye. Fersman pointed out that:}

"The rare elements, particularly tin, bismuth, tungsten, and to some extent molybdenum, tantalum and the rare earths, by the laws of geochemistry are derived from the final extracts of granitic magmas. They are often associated with gold, and therefore gold deposits as well as deposits of tin, tungsten and bismuth are associated with one another in areas of granite intrusives; during the erosion of granites, minerals containing these metals find their way into the black magnetic sands from which gold is commonly recovered. The old fashioned methods of gold mining were not concerned with these black sands, but in some of our districts these sands containing up to 50 percent cassiterite constitute a source of this metal previously unexploited. Considering that up to 5000 tons of black sands have passed through the gold sluices of Siberia, and that in some districts cassiterite is present in considerable quantities, as in northwest Pamir, the upper parts of the Kolyma and Indigirka rivers, and in the Kharginsk district at Selendzha, it becomes apparent that each year we have lost. several hundreds of tons of valuable metals from these placers. Bismuth in addition to tin is found in gold sand (in the Kariysk district of Transbaikal), as well as monazite, which is the source of the rare earths and thorium (in the Undy and Kochkari district in the southern Urals), and in many places large quantities of wolframite ore, scheelite, and other minerals. The heavy minerals of gold placers, although they constitute a most valuable source of raw material for the entire rare-metal industry, have been poorly studied and have not been conserved as they are usually discarded after the gold is recovered.

"One of the greatest tasks of our gold industry is to master this new problem in a technical and practical way in order to utilize all minerals that are contained in the placer deposits. "

The presence of rare and precious minerals in our alluvial deposits necessitates widespread sampling and investigation of black sands, as well as development of equipment for the concentration and separation of heavy minerals,

Heavy-mineral separation is not only a method for the winning of economic minerals, but is a guiding star in prospecting for nonferrous metals and rare earth minerals. In spite of the recency of its development, heavy-mineral analysis is of widespread importance in the U. S. S. R. today. For example, the data of P. S. Sasim in western Siberia show that in the two-year period, 1931-32, the application of heavy-mineral method in prospecting has resulted in the discovery of 500 monazite prospects, 150 tungsten prospects, 50 cassiterite prospects, 30 
cinnabar prospects, 10 prospects of platinum and metals of the platinum group, and 8 fergusonite prospects.

In central Asia several mineral deposits containing cassiterite, scheelite, columbite-tantalite, and other valuable minerals have been found by the heavy-mineral method.

In 1933 in the central Zeysk mining district of the Far East, we found at "Bych'yem Klyuch" 175 gold colors in a four-gram sample, and at the "Podgorny" mine, 112 gold colors in a 1.2-gram sample.

If we consider that in neither case had the gold been sluiced, then it is reasonable that the source deposit is near the alluvial sands. Needless to say, these alluvial sands deserve attention.

In 1927 in the northeast Transbaikal district, N. A. Khrushchev found black sands containing gold, bismuth, mercury, molybdenite, wolframite, scheelite, monazite, galena, and bismuthinite.

The northern Caucasus district, where the black sands were sampled in detail, showed the presence of cassiterite over a large part of the district.

An exploration of the Ural'skiy Khrebet [ Ural Mountains] for the specific purpose of determining the extent of cassiterite in placer deposits showed that cassiterite is found in the Aydyrli, Gumerov, and Kochkar districts of the Yuzhnyy Ural; in the Alapayev district of the Sredniy Ural; and in the Severnyy Ural. Although this cassiterite does not occur in economic concentrations, its presence has enabled industrial organizations and geological trusts to undertake exploration for cassiterite using the new developments in prospecting technique.

Valleys containing ancient alluvial deposits and Mesozoic terraces should be investigated with particular care.

Investigations of river channels, ancient terraces, and also the more recent deposits should be carried out in the Soviet Union, because we are well aware that throughout the world, 80 percent of the cassiterite production is obtained from alluvial deposits, whereas the investigation of our alluvial deposits in the Soviet Union is far from satisfactory.

All the ramifications of heavy-mineral analysis are not covered by the above article, but the data given should suffice to show that the heavy-mineral method ought to assume a leading role in the exploration for nonferrous and rare metals, especially in poorly explored and sparsely populated regions. While the heavy-mineral method does not permit complete evaluation of the geology of a region, it will permit conclusions to be drawn regarding the type of rocks present, the character of the mineralization, and the economic importance of the mineral deposits.

\section{Types of Placers and the Paragenesis of} Minerals in Blac $\bar{k}$ Sands

Sands which result from the weathering of rock usually do not remain in place but are transported by water, wind or other agents. During transport they are sorted according to grain size and specific gravity. Uneven river bottoms and other causes tend to check the motion of the mineral grains. They settle and are sorted according to specific gravity, resulting in the separation of valuable minerals. Concentrations of minerals in this way often constitute commercial ores, and are spoken of in industry as placers. According to their structure, placers may be classified as unconsolidated or as hard placers which have cemented and compacted into rocks, such as conglomerates.

Placers can be classified according to origin as follows:

Alluvial placers: Composed of pebbles, gravels, sands, and clays deposited by flowing waters. In the process of transportation the heavy and insoluble minerals are concentrated in the sands.

Eluvial placers: Composed of weathered rock which has remained in place.

Eolian placers: Composed of wind-deposited material in which the heavy-mineral particles are deposited not far from their sources.

"Deluvial" placers: Composed of sediments depcsited by waters flowing down mountain sides. Heavy-mineral particles are deposited either on mountain slopes or at the base of mountains.

Diluvial placers: Composed of material derived from the erosion and crushing of rocks by glaciers.

Marine placers: Composed of sands which have been formed and also enriched with heavy minerals by ocean waves and the tide.

According to the data of V. I. Vernadskiy all these types of placer deposits have different characteristics and may be clearly distinguished in nature. The distribution of valuable heavy minerals varies within them. Thus, in eolian sands, they are found near the surface, where the finer particles are blown away; in alluvial placers they are found at the bottom where they have been disseminated in black sands by currents of flowing water.

The association of minerals in sands does not represent a random collection of individual. components, having no relation to each other. At the close of the eighteenth and beginning of the nineteenth century, French and British mineralogists, such as Delille Haüy, Price, Jameson, and others developed the theory that the discovery of one mineral could lead to the discovery of others, because of their mutual association.

A student of Werner named Breithaupt, who was the principal innovator of the study of mineral associations, combined the individual ideas and developed the theory of paragenesis. 
"The doctrine of paragenesis is the basis of contemporary mineralogy. Only by an exact and complete study of paragenesis of minerals is one able to construct generalizations in this field of science." The occurrence of one mineral serves as a guide to others of possible economic importance.

The association of minerals in sediments and placers enable one not only to determine the type of rock from which the mineral is derived, but also to predict, on the basis of theory, which other minerals will be found there.

In this manner, the role of paragenesis in the study of alluvial deposits is just as important as it is in the study of minerals in primary deposits.

Table 9 shows the accessory minerals and parent rocks associated with the valuable minerals of placer deposits (according to Milner).

Although this table is not complete, it may be used as a guide to valuable minerals found in alluvial placers.

By taking into account mineral associations in sedimentary materials, we have recently found new minerals in the black sands of the Il'men forest preserve which up to this time were unknown in the mountains of Il'men. These include cassiterite, cinnabar, native mercury, and platinum. It is true that the above-mentioned minerals were not of economic importance, but they deserve attention from the mineralogical and geochemical point of view, and the fact that they were discovered in placers once more emphasizes the importance of this method.

\section{Methods of Field Investigation}

The presence of rare and valuable minerals in sands presents prospecting and research organizations with problems of mass sampling and the determination of mineralogical content of placer material. First, the alluvial, eluvial and deluvial placers should be thoroughly sampled. Surveys of alluvial placers in our work were usually begun at the mouths of springs and rivers, including the tributary streams, if such were found on the way to the upper part of the river. Experience shows that a detailed investiqation of a given district by the heavy-mineral method is possible only when the heavy-mineral samples are obtained from test pits. Black sands collected directly from the mouth of a river do not give satisfactory results with respect to the quantity and mineral content of the heavy concentrates. It is impossible to predict where to dig test pits, as this depends on the geologic conditions and the relief of the region. In practice we dug several test pits, spaced 20-25 meters apart along

Table 9. --Gangue and country rock associated with placer deposits

\begin{tabular}{|c|c|c|c|c|}
\hline Group & $\begin{array}{l}\text { Ore } \\
\text { minerals }\end{array}$ & Gangue minerals & Country rocks & Remarks \\
\hline 1 & $\begin{array}{l}\text { Platinum, iridium, } \\
\text { osmiridium, } \\
\text { palladium. }\end{array}$ & $\begin{array}{l}\text { Magnetite, chromite, } \\
\text { picotite, olivine, } \\
\text { pleonaste, serpentine. }\end{array}$ & $\begin{array}{l}\text { Peridotite, basic gabbro, } \\
\text { dunite, serpentine rocks. }\end{array}$ & $\begin{array}{l}\text { Presence of } \\
\text { ultrabasic rocks } \\
\text { may be an indictor. }\end{array}$ \\
\hline 2 & Gold. & $\begin{array}{l}\text { Pyrite, pyrrhotite, } \\
\text { galena, chalcopyrite, } \\
\text { concentrates rich in } \\
\text { magnetite. Minerals } \\
\text { of group } 1 .\end{array}$ & $\begin{array}{l}\text { Quartz veins, associated } \\
\text { with various igneous } \\
\text { rocks. Conglomerates, } \\
\text { granites (seldom). }\end{array}$ & \\
\hline 3 & $\begin{array}{l}\text { Cassiterite, } \\
\text { wolframite, } \\
\text { tantalite. }\end{array}$ & $\begin{array}{l}\text { Tourmaline, topaz, } \\
\text { fluorite, monazite, } \\
\text { scheelite, molybdenite, } \\
\text { ilmenite, magnetite, } \\
\text { lepidolite. }\end{array}$ & $\begin{array}{l}\text { Veins and ores, } \\
\text { pegmatites, granites. }\end{array}$ & $\begin{array}{l}\text { Abundance of } \\
\text { topaz, lepidolite, } \\
\text { or mica with or } \\
\text { without fluorite is } \\
\text { an indicator. }\end{array}$ \\
\hline 4 & Diamonds. & $\begin{array}{l}\text { Ilmenite, serpentine, } \\
\text { magnetite, chromite, } \\
\text { picotite, pyrope, garnet, } \\
\text { olivine. }\end{array}$ & $\begin{array}{l}\text { Basic igneous rocks, as } \\
\text { peridotite; conglomerate } \\
\text { (seldom). }\end{array}$ & r \\
\hline 5 & $\begin{array}{l}\text { Corundum, ruby, } \\
\text { sapphire. }\end{array}$ & $\begin{array}{l}\text { Amethyst, topaz, beryl, } \\
\text { chrysoberyl, garnet, } \\
\text { spinel, rutile. }\end{array}$ & $\begin{array}{l}\text { Crystalline dolomite, } \\
\text { metamorphosed lime- } \\
\text { stone, pegmatite, syenite. }\end{array}$ & \\
\hline 6 & Monazite. & $\begin{array}{l}\text { Ilmenite, zircon. } \\
\text { Minerals of group } 5 \text {. }\end{array}$ & $\begin{array}{l}\text { Pegmatite, gneiss, } \\
\text { granite. }\end{array}$ & \\
\hline 7 & $\begin{array}{l}\text { Emerald, } \\
\text { chrysoberyl, } \\
\text { alexandrite, } \\
\text { garnets. }\end{array}$ & $\begin{array}{l}\text { Tourmaline, lepidolite, } \\
\text { topaz, pyrite, spinel, } \\
\text { amethyst. Minerals of } \\
\text { group } 4 \text { and } 6 .\end{array}$ & $\begin{array}{l}\text { Granite, pegmatite, } \\
\text { limestone, gneiss, } \\
\text { schists. }\end{array}$ & \\
\hline
\end{tabular}


a line. If the valleys were wide, the distance between lines was 1.5-2 kilometers. In some valleys a grid of test pits was laid out at a spacing of 500-600 meters. In the test pits, 60-to 100-kilogram samples from each half meter of depth were collected and washed. It is very desirable that the geologist or prospector have first-hand experience with panning out the heavy minerals from the sample. Many investigators think that the method of obtaining the heavy concentrates is a simple matter, and trust the panning process to unqualified persons. Improper washing technique will give a distorted picture of the mineralogical content of the heavy concentrate because through carelessness a large part of the heavy components will be washed away with the lighter fraction. This will result in an incorrect evaluation of the placers, or will lead to incorrect conclusions in the course of prospecting an area for primary mineral deposits.

The actual process of obtaining heavy minerals from placers was carried out with the following simple implements: an Asiatic pan, a so-called. "koreysky" pan, and a washer. The pans are made of either thin sheet metal or wood; linden or poplar wood is best.

The steel pan which we used in our work proved somewhat inconvenient, partly because of lower recovery of heavy minerals, and partly because the washing process is less convenient due to the small size of the handle. Wooden troughs are more convenient. They are usually 0.6-0.7 meter in length, 0.3-0.4 meter in width and have a depth of $0.15-0.2$ meter. This size trough will hold from 12 to 16 kilograms of rock.

The trough is filled with rock and lowered into a pool of water which should be somewhat deeper than the trough (in running waters small excavations sometimes have to be made). The material in the submerged trough is broken up either by hand or, better still, with an iron rake. The large fragments are taken out for examination, and if barren are discarded.

From time to time the trough is moved sharply back and forth, and again the material is loosened with the small rake. As a result, the heavy particles settle to the bottom of the trough, and the light particles rise to the top and are carried away by the water. This concentration process is continued until only fine gravel remains in the trough.

The operator then takes the trough, tips it slightly holding it on the surface of the water, turns it around with circular motions, shakes it, and lowers it in a tipped position into the water. By repeating these manipulations, he finally obtains a heavy concentrate at the bottom of the trough.

In addition to the trough we have also used the Asiatic pan which seems to be preferred in the Ural Mountains, although in the Far East the prospectors all use troughs. The Asiatic pan is a simple iron pan with high edges and a flat bottom. Large Asiatic pans hold as much as 12 kilograms of rock. The process of washing sands with a pan does not differ much from the process of washing sands with a trough. The pan is filled with rock and lowered into the water. While one hand is holding the handle of the pan, the other hand shakes the opposite edge of the pan with rapid motions to the right and left, to break up the clots.
In order to loosen the material thoroughly, an iron scraper or hoe is sometimes used. The fine, heavy parts settle to the bottom, the light particles rise to the top and are carried away by the water. Clay and mud as well as fragments of various sizes are removed by means of a rotary stirring motion until a pure concentrate is obtained.

In addition to the implements described above, we have also used an ore concentrator or washed in our work. We must add, however, that the washer was not used very often. It is useful in work at a more or less permanent camp where the object is to extract valuable minerals such as gold, platinum, iridium, and others. In exploration work, where the object is to determine the complete mineralogical content of black sands and to trace the distribution of minerals throughout an entire valley, as well as determine the mineralogical content of each individual test pit, an ore concentrator is not practical. However, washing with an ore concentrator is, of course, much more accurate than washing with a trough or pan. We have been using the ore concentrator exclusively for the purpose of determining the abundance of gold and platinum, and have not tried to determine the complete mineralogical composition of the heavy concentrates because even if we had found cassiterite, for example, in the concentrates, we could not trace its origin if the mill feed had come from different sources. To conduct a survey by taking the material to an ore concentrator for washing would require too much time and be very impractical.

The heavy concentrates washed out by one of the above methods were dried either on paper in the sun, or over a fire in the same pan in which it was concentrated. A fire was used especially on cloudy and damp days. If cinnabar is present, the warming or drying must be done very cautiously to prevent it from volatilizing. The dried concentrate is placed into a $12 \times 6$ centimeter sample bag. A label is affixed to the sample bag to indicate the place from which the sample was taken, the number of the test pit, the quantity of material washed out in the troughs or pans, the date the sample was taken, and the name of the person who did the panning.

To determine the genetic relation of heavy minerals to parent rocks, we have usually prepared artificial gravels; in the field, we have sampled country rocks as well as vein derivatives such as quartz, pegmatite veins, aplites, contact rocks and other vein phenomena. This enabled us not only to determine the genetic relationship, but also to study in detail the accessory minerals of intrusive and extrusive rocks.

The rocks were crushed in a Blake crusher, and then ground to a size of $1 \mathrm{~mm}$ in a mortar. Not less than 25-30 kilograms of rocks were taken for crushing, and if the rock appeared important from a mineralization standpoint up to 50 kilograms were taken.

In making a thorough investigation of the mineral resources, metallurgy, geochemical processes, mineralogy, geology, and petrology of an area, each investigator should apply the method of heavy-mineral analysis as well as the usual methods of study. Each geologist should be required to collect heavy minerals from both gravels and rocks. To show how informative heavy-mineral analysis can be, we give in table $10 \mathrm{com}-$ parative lists of minerals reported in the literature and takenfrom our research on the heavy minerals in pits 
Table 10.--Comparison of minerals of the Ilmen forest preserve reported in the literature and those in heavy concentrates

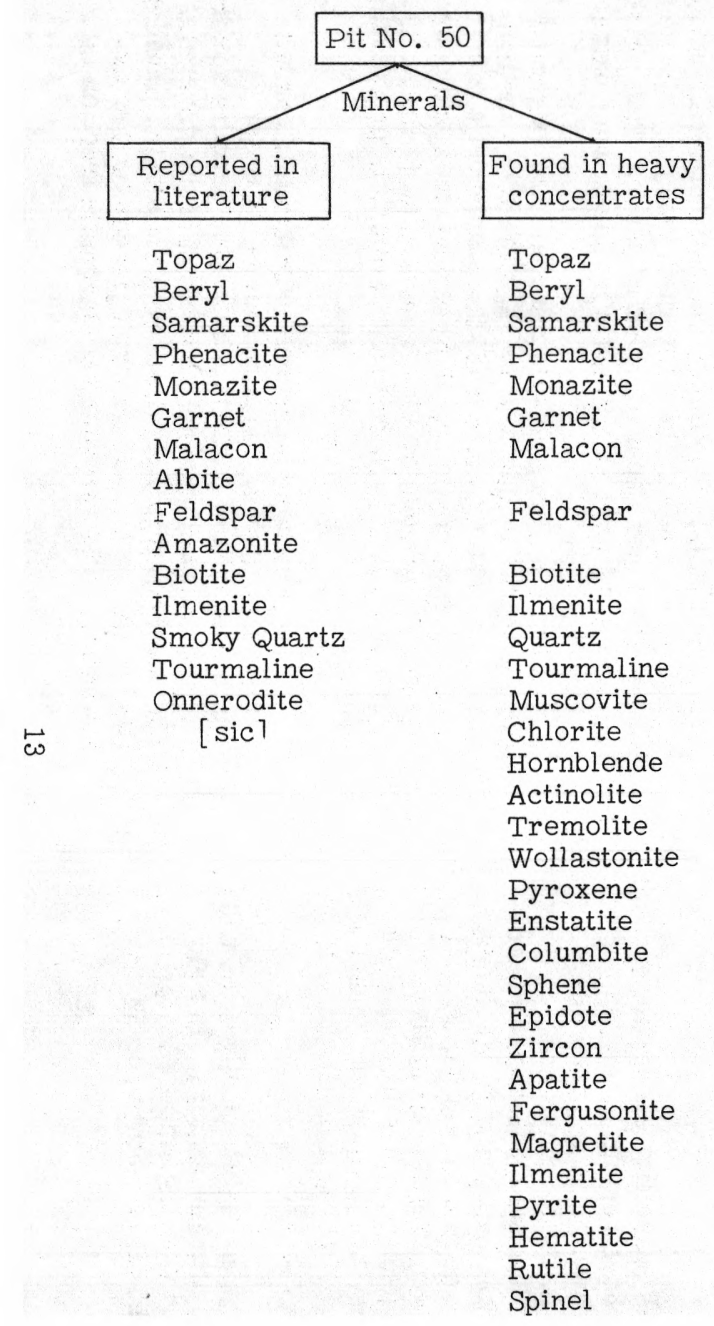

\begin{tabular}{|c|c|c|c|}
\hline $\begin{array}{l}\text { Reported in } \\
\text { literature }\end{array}$ & $\begin{array}{c}\text { Found in heavy } \\
\text { concentrates }\end{array}$ & $\begin{array}{l}\text { Reported in } \\
\text { literature }\end{array}$ & $\begin{array}{l}\text { Found in heavy } \\
\text { concentrates }\end{array}$ \\
\hline $\begin{array}{l}\text { Malacon } \\
\text { Columbite } \\
\text { Albite } \\
\text { Amazonite } \\
\text { Quartz }\end{array}$ & $\begin{array}{l}\text { Malacon } \\
\text { Columbite } \\
\text { Feldspar } \\
\text { Quartz } \\
\text { Limonite } \\
\text { Corundum } \\
\text { Muscovite } \\
\text { Topaz } \\
\text { Zircon } \\
\text { Sinets [ sic] } \\
\text { Rutile } \\
\text { Magnetite } \\
\text { Ilmenite } \\
\text { Biotite } \\
\text { Garnet } \\
\text { Cassiterite } \\
\text { Epidote } \\
\text { Pyrite } \\
\text { Tourmaline } \\
\text { Hematite } \\
\text { Hornblende } \\
\text { Sphene } \\
\text { Monazite }\end{array}$ & $\begin{array}{l}\text { Beryl } \\
\text { Quartz } \\
\text { Feldspar } \\
\text { Smoky Quartz }\end{array}$ & $\begin{array}{l}\text { Beryl } \\
\text { Quartz } \\
\text { Feldspar } \\
\text { Biotite } \\
\text { Cassiterite } \\
\text { Topaz } \\
\text { Sphene } \\
\text { Pyroxene } \\
\text { Hornblende } \\
\text { Tourmaline } \\
\text { Zircon } \\
\text { Epidote } \\
\text { Apatite } \\
\text { Magnetite } \\
\text { Specularite } \\
\text { Molybdenite } \\
\text { Pyrite } \\
\text { Muscovite } \\
\text { Garnet } \\
\text { Ilmenorutile } \\
\text { Columbite } \\
\text { Pyrochlore }\end{array}$ \\
\hline
\end{tabular}


number 50, 72 and 101 in the Il'men forest preserve.

This table shows that more minerals were tound in the heavy concentrates than had been reported before the application of heavy-mineral analysis. It is not reasonable to assume that the increased number of minerals found in the heavy concentrates from these pits was due to increments from other places, since the number of heavy minerals found in the sands is the same as the number of heavy minerals found in the crushed rocks from the same pits. The number of heavy minerals obtained from crushed rock will obviously exceed the number of minerals observed in a thin section of the same rock.

\section{The Study of Heavy Minerals in the Field}

Heavy-mineral concentrates ought to be studied on the spot in field laboratories, especially the economic deposits. The presence of an economic mineral enables estimation of its distribution and possible economic value. Modern prospecting for important economic minerals such as cassiterite, wolframite, scheelite, galena, silver, gold, and others, requires a small portable laboratory for each prospecting geologist and research scientist. Reaction tests for the minerals mentioned above are simple and do not require complicated equipment. After returning from the expedition, detailed analysis of the entire mineralogical content of the heavy concentrates is made by means of separate processes.

Under field conditions it is not necessary to make a complete separation of the sample into constituent minerals but for rapid examination of heavy minerals, a rough separation may be made.

The magnetic fraction may be separated with a simple horseshoe magnet, and the electromagnetic fraction may be separated by a field electromagnet, with which 15 fractions can be obtained.

The field electromagnet weighs 8-10 kilograms. It does not require an external electric circuit, but is charged by flashlight batteries. We will not give a detailed description of this magnet, since in principle it is similar to the electromagnet described in detail below.

Minerals such as scheelite, casserite, zircon, rutile, galena and others remain in the nonelectromagnetic residual fraction, and are determined comparatively easily in the field. In order to detect scheelite, which has often gone undetected under field conditions, G. Komovskiy and F. Abolenskiy constructed a portable device with an ultraviolet lamp which enabled them to detect scheelite by its light blue radiation. It is true that diamonds give a light blue fluorescence, but these two minerals are never confused, even by individuals who know little of mineralogy (see p. 212-213).

There is no doubt that this device will be widely used in investigations of many regions. In field practice it provides us with the only indicator for scheelite, which by the other methods could be overlooked.
These devices are manufactured by the mechanical workshops of the Institute of Geological Sciences, Academy of Science. Another device invented by G. Komovskiy to detect scheelite, zircon, diamonds and other minerals by their radiation properties, is the field cathode unit. This device is very useful in the field.

It consists of a hand-driven vacuum oil pump, a flywheel which drives a 15-kilowatt generator with a belt, and a cathode tube with a hose connection to the vacuum pump. The material to be examined is placed in the cathode tube. The hand-driven flywheel pumps out the receptor until maximum vacuum is obtained. If the specimen contains scheelite, it will be easily detected by its intense light blue radiation. This unit is manufactured by the same organization mentioned above. There is no doubt that both of these devices will be of great help to the prospector and research worker in their practical work.

Sometimes it is necessary to examine minerals and rocks for radioactivity in the field. The sample to be examined may be placed in the receptacle of an electroscope. The electroscope is charged by an ebonite rod. The amount of radioactivity of the given sample is determined by the rapidity with which the "leaves" fall in the electroscope. (See page 228).

\section{The Separation Process}

To speed up the processing of heavy-mineral concentrates, the following chart has been worked out on basis of practical experience (fig. 46). The heavy concentrate, which has been collected at some prospect in the field, is weighed, and if too large is reduced by quartering. This is done by mixing, spreading on paper, and dividing into four equal parts; if it appears that the quarter remaining is larger than what is required for examination, the process is repeated.

We have used 25-gram portions (or less if that much were not available) of heavy-mineral concentrates for examination. Usually, after obtaining an average sample, the magnetic minerals were extracted with a horseshoe magnet as follows: The magnet was held over a layer of the sample grains spread out on glass; the poles of the magnet were either covered with paper or were simply separated by a sheet of clean paper from the sample. The highly magnetic minerals would stick tc the paper at the poles of the magnet, and could be deposited on a separate sheet of paper. This process was continued until all magnetic minerals were extracted.

Very often nonmagnetic minerals are extracted along with the magnetic ones, and the above method must be repeated to eliminate the nonmagnetic minerals. The magnetic fractions are weighed and poured into small packages which are labeled as follows: Magnetic fraction, Cheremshanka district, prospecting pit no. 2.

The remaining nonmagnetic fraction is passed through a number of standard sieves, in order to obtain fractions of uniform size. This permits a more complete electromagnetic separation of the minerals. The coarse fraction obtained from the sieving is weighed, labeled and sent to the mineralogist for further examination. The remaining nonmagnetic fraction is 


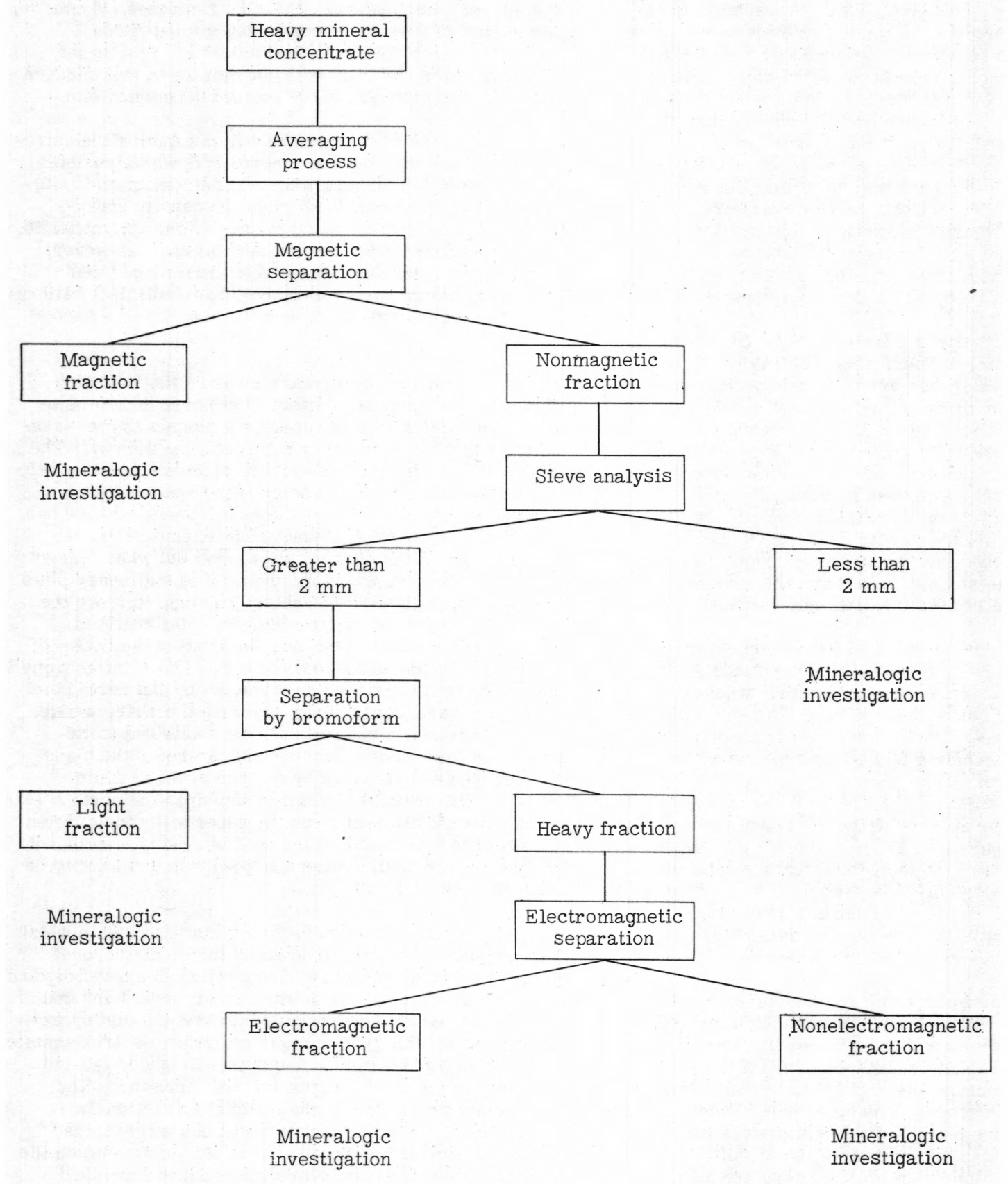


placed in a funnel containing bromoform. The minerals which have a higher specific gravity than the bromoform (2.9) settle to the bottom of the funnel, and the minerals with a lower specific gravity rise to the top. The extracted light fraction is labeled and then submitted for a mineralogical analysis. The heavy fraction is further concentrated into constituent minerals by the electromagnet. In our work, only bromoform was used as a heavy liquid, but often there is a need for liquids with specific gravity greater than bromoform, such as:

1. Methylene iodide, $\mathrm{CH}_{2} \mathrm{I}_{2}$, specific gravity: 3.3. Next to bromoform this is the most suitable solution. It has a lavender-red color and like bromoform it disintegrates in light, becoming brown.

2. Sushin-Rohrbach solution, composition:

$\mathrm{BaI}_{2}+\mathrm{HgI}_{2}+\mathrm{H}_{2} \mathrm{O}$ specific gravity: 3.5.

3. Mercuric nitrate, specific gravity: 4.3. $\mathrm{A}$ poisonous compound, solid at room temperature, becomes liquid at $70 \mathrm{C}$.

4. Thallium-silver nitrate, $\mathrm{TlAgN}_{2} \mathrm{O}_{6}$, flux with a melting point of $75 \mathrm{C}$, specific gravity: 4.8 . Very soluble in water. Is used in liquid form, whereby the heavy fraction sinks to the bottom of the vessel, and the light fraction rises to the top. When it solidifies the upper and lower parts of the solid flux may be cut apart, and the minerals are obtained by melting these parts of the flux in water.

5. Thallium-mercury nitrate, $\mathrm{TlHgN}_{2} \mathrm{O}_{6}$, specific gravity: 5.3 , fuses at 76 C. It is used chiefly for the separation of ilmenite, magnetite, pyrrhotite, pyrite and monazite from the minerals: columbite, scheelite, wolframite, and cassiterite.

All of the above mentioned fluxes and solutions, especially numbers 1,3 and 5 , should be stocked by heavy-mineral laboratories, particularly where a complete mineralogical determination of heavy minerals is made. The separation of the heavy fraction from the light with bromoform is well known, and will not be described here.

The residue obtained from the bromoform separation is separated into constituent minerals by an electromagnet. This facilitates further determinations of mineral content. We have used an electromagnet manufactured by the magnetic laboratory of the State university of Moscow, and designed by the director of that laboratory, N. S. Akulov.

The electromagnet has a rectangular core of soft transformer iron, 42 centimeters on a side with a cross section of $9.5 \times 9.5$ centimeters. One side of the core is wedge-shaped and forms one of the poles of the electromagnet. The angle between the edges of the wedge is 45 degrees. The other pole of the electromagnet is a square plate $10 \times 10$ centimeters and 2 centimeters thick. This plate is fixed directly under the wedge. The dimensions of the core are such that two coils can be wound upon it. The second coil can be used either to increase the field or to demagnetize it. The main coil has 1700 ampere turns of P. B. D. [sic] wire, diameter of $1.5 \mathrm{~mm}$. The weight of the wiring with its insulation is 16.5 kilograms. The winding consist of two parallel sections, each having independent connections, which enables one to unite them in either series or parallel. The height of the coils is 28 centimeters. The coil is fed by 7 to 8 ampers direct current. Because we had to use alternating current, we used a motor generator set for rectification. The electromagnet, of course, was equipped with an ammeter and sliding-contact rheostats. The rheostats enabled us to regulate the strength of the current and to determine in this manner what current strength attracted certain minerals.

One of the best features of N. S. Akulov's electromagnet is the fact that the wedge-shaped bar enables one to obtain the largest gradient of the magnetic field. With this electromagnet we could frequently obtain completely pure mineral fractions of titanite; monazite, ilmenite, hornblende, garnet, and others. However, some of the fractions contained impurities of other minerals, which can be attributed to insufficient calibration of our electromagnet, and the absence of a second coil.

The separation was carried on in the following manner: the current was turned on; beneath the pole of the vertical wedge-shaped bar a glass was placed on which a thin layer of heavy minerals was spread. The glass with the sample was placed upon the square plate. The distance between the poles was regulated by a screw, which lowered and lifted the wedge-shaped bar. The sliding-contact rheostats enabled us to regulate the strength of the current and to find out what current strength attracted which mineral. The stationary plate allowed us, without the slightest jarring, to move the glass slide with the sample in different directions beneath the point of maximum field strength of the north pole of the wedge-shaped bar. The electromagnetic particles of the sample are attracted by the north pole and distributed in a uniform layer on the sharp wedge. After the pole has gathered all the electromagnetic minerals for a particular current strength, the glass is removed and replaced by a clean sheet of white paper. The grains which are clinging to the north pole of the electromagnet fall on the paper after the current is switched off. Some of the grains, owing to remnant magnetism, remain on the sharp edges, and have to be removed with a brush.

In order to be sure that no minerals remain which are capable of being attracted by the electromagnet for a given current strength corresponding to a given distance between the poles, this operation is repeated several times until electromagnetic grains are completely extracted under the given conditions. The electromagnetic fraction extracted in this manner is weighed, labeled and sent to the mineralogist for examination. The remaining part of the electromagnetic fraction is subjected to a similar process with a corresponding change of current strength and the distance between the poles. With the aid of the electromagnet described above we have been able to obtain up to 15 mineral fractions from heavy residues. This has considerably facilitated the mineralogic analysis of the sediments. The results of our experiments upon the electromagnetic separation of different minerals and their tendency to be attracted by the electromagnet as a function of the distance between poles are listed in table 11 . 
Table 11. --Electromagnetic data for the separation of minerals

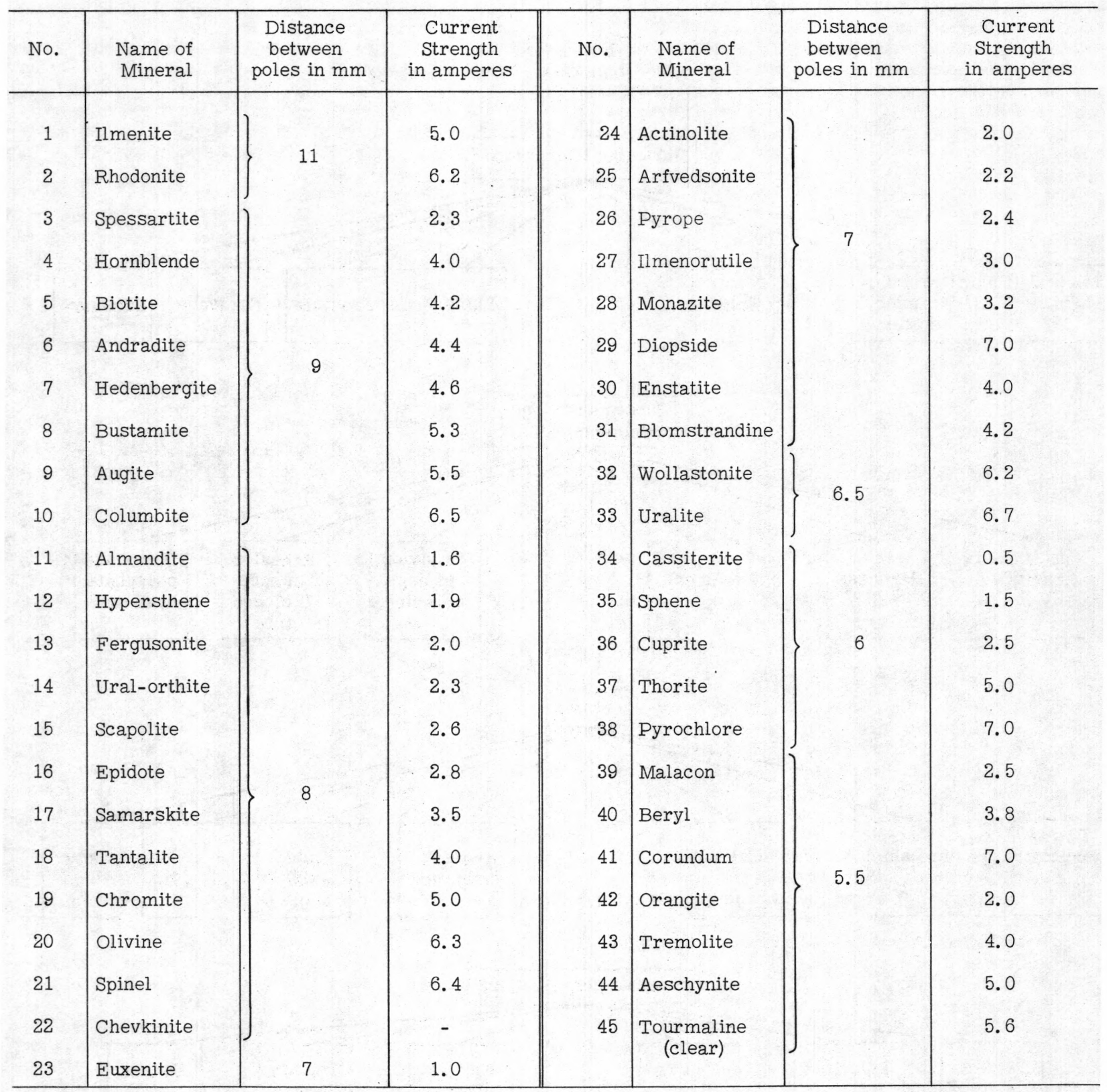



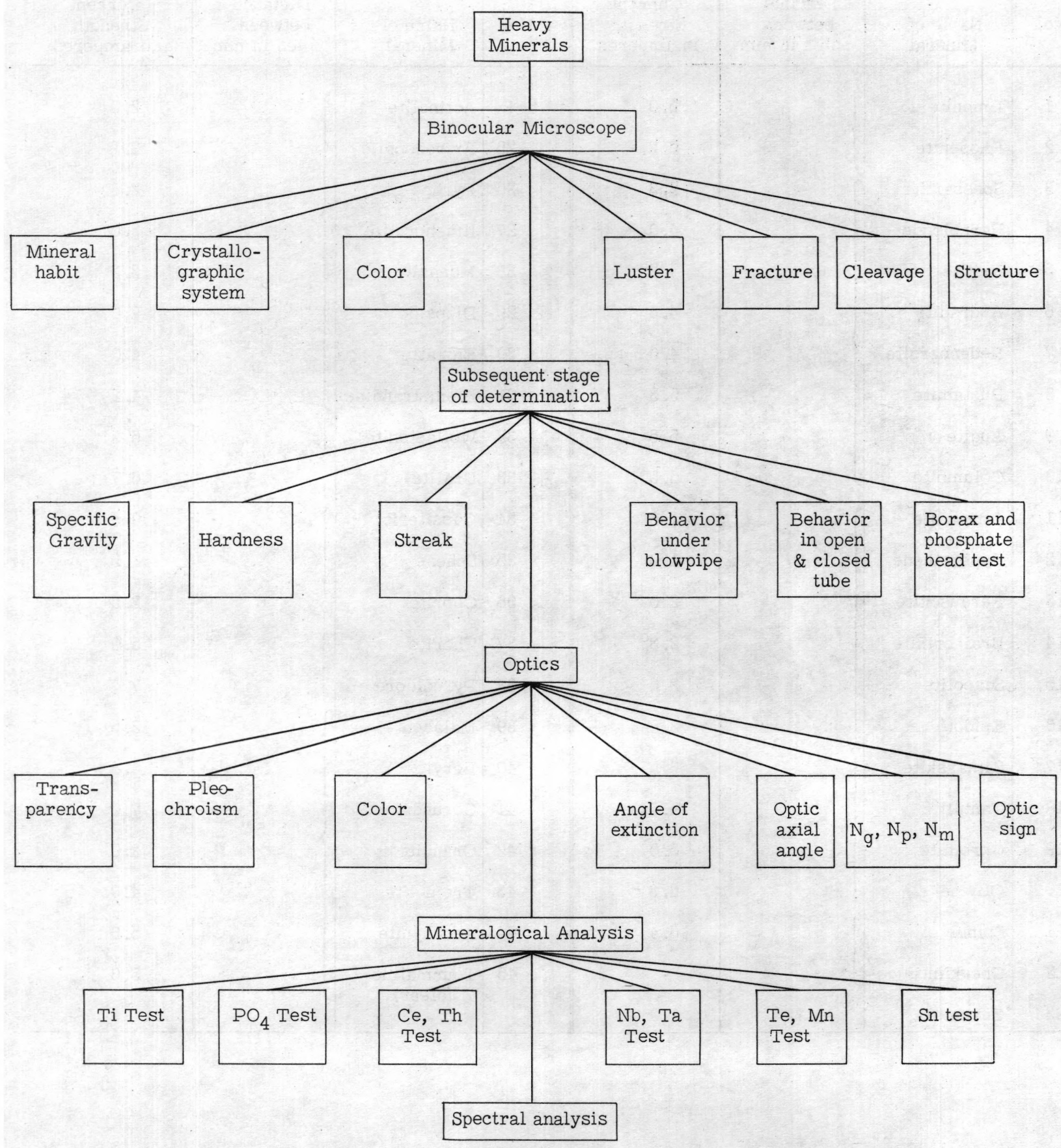
Determination of the Mineral Content of Heavy Concentrates

The successive separations yield these products: magnetic fraction, nonmagnetic fraction of grain size greater than $2 \mathrm{~mm}$, light fraction, electromagnetic fraction, nonelectromagnetic fraction.

After these separations have been made, the mineral composition of the fractions is studied with the binocular microscope and blow pipe. A preliminary examination was performed with these two instruments, and if there was doubt regarding a certain mineral, additional methods of identification were used. (Diagram 49) Mineral determination by means of the binocular microscope involved study of its external form and physical properties, that is, the external appearance of the mineral, its crystallographic form, color, luster, fracture, cleavage and structure.

If these procedures were insufficient to determine the mineral, it was tested by Moh's scale of hardness; the color of the streak was determined; a blow pipe analysis was made; the specific gravity was determined; and in rare cases, goniometric measurements were taken.

Besides these procedures we often used the immersion test, which was of great help in identifying the transparent minerals. This test consists of the following procedure: The unknown mineral is transferred to a microscope slide with a watercolor brush or a needle. If the grain is too large, it is crushed either on the slide or in an agate mortar. The fragments are put under a cover glass beneath which is placed an immersion liquid with an index of refraction close to that of the mineral. If the index of refraction of the liquid is larger or smaller than that of the mineral, it is removed from the slide with filter paper and replaced by another liquid. Frequently, when withdrawing the liquid from the slide; the fragments are drawn to the edges with the liquid, so that either the cover glass has to be shifted or another grain taken. To avoid this, place the fragments in a drop of water on the slide so that after evaporation the fragments stick to the slide.

Microscopic analysis is used to determine pleochroism, color, dispersion effect, angle of extinction with respect to its elongation or cleavage, and the optic sign. Similarly the "osnost'", the principle optical axis and optic sign, of the mineral were determined with a no. 7 objective. For determining minerals whose indices of refraction were higher than our solution (1.783), we used fusions. Sometimes simple microchemical analyses were made, especially to determine the rare earth and opaque minerals.

Spectroscopic analysis was used to determine minerals of doubtful identity, which frequently include rare earth minerals.

Fluorescence of minerals was determined with a stationary cathode-ray unit, consisting of a cathoderay tube and a screen. This apparatus, designed by G. Komovskiy, permits the luminiscence of minerals to be observed through a pane of glass by means of magnifying devices such as the microscope or the binocular lens. The cathode-ray tube and screen was large enough to allow not only small objects to be irradiated, but lumps of ore as large as 10x10x3 centimeters. For further description of the cathoderay apparatus, reference is made to the work of G. Komovskiy and F. Abolenskiy, published in the journal "Soviet Geology", 1938, No. 4, pp. 207-214.

To detect scheelite in hand specimens and heavy concentrates we used the stationary ultraviolet-ray apparatus at the Institute of Geological Sciences, Academy of Science.

\section{Determination of Heavy-Mineral Content of the Sample}

The percentage of heavy minerals in sedimentary material is proportional to the ratio of weight of the heavy minerals to the weight of the original sample. This determination demands extreme care because of loss of part of the heavy minerals in washing. We determined the percentage yield of each particular mineral as follows: with the help of an intergrating stage, by the ratio of the weight of the particular mineral fraction to the total weight of the heavy minerals', by a count of the individual grains in each fraction.

In order to make a quantitative calculation of luminescent minerals, E. Razumna suggested the following: luminescent analysis by means of a comparison standard; luminescent analysis by means of the zero point method of calculation.

Widespread mapping of heavy mineral concentration will better reveal the extent of economic placer deposits, and will add to the knowledge of halos of dispersed metals about primary ore deposits.

In his paper upon exploration for rare metal deposits in Siberia, F. N. Shakhov describes in detail the character of the heavy mineral assemblage in relation to the type of sands, the method of obtaining heavy mineral concentrates, and the method of compiling the heavy mineral map, that is, plotting the geochemical as well as the mineralogic data on the geologic map.

Similar large scale investigations, especially in the Ural Mountains and in western Siberia, show that, by compiling accurate maps of heavy minerals and contouring so as to indicate places of maximum concentration for each element or mineral, areas which require futher exploration may be selected. By study of the typomorphic characteristics of crystals, the presence of definite genetic types of primary deposits may be revealed.

Heavy-mineral maps of river systems allow one to determine those tributaries which drain regions containing primary mineral deposits.

\section{Bibliography}

Abikh, Mestorozhdeniye magnitnogo zheleznyaka na beregu Chernogo moriya [Deposits of magnetic iron on the shores of the Black Sea]: Gorn. zhurn, 1856, ch. 3 .

Bazhenov, K., Promyvka shlikhov [ The washing of heavy minerals], Izd. Zap.-Sib. geol. -razved. trudy, Tomsk, 1932. 
Bilibin, Yu. A., Osnovy geologii rosspey [The basic geology of placers], GONTI 1938, pp. 487-496. Voprosy issledovania shlikhov [Problems of investigating heavy minerals]: Mat. soveshch. Glavgeol. v Inst. Miner. syr'ya 14-16/IV, 1936, ONTI 1937.

Voronova, Ye. A. and Zeeman, G. V., O metodike issledovanya shlikhov [ On methods of investigating heavy minerals 1: Izv. Vses. Geol.-pazv. ob"yed., 1931, vyp. 64.

Zeeman, G. V. and Lur'ye, M. L., Instr. po sostavleniyu shlikhovykh kart [Instructions upon the compiling of heavy mineral maps 1: Tsentral'. nauch.- issledov. geol. -razved. inst., 1938, pp. 1-48.

Igumnov, A. N., Izucheniye mineralogicheskogo sostava ural'skikh shlikhov (Studies of the mineralogical composition of Ural heavy minerals): Izv. Vses. geol. razv. ob"yed, 1931, vyp. 64.

Komovskiy, G. and Abolenskiy, F. , Lyuministsentsya mineralov i apparatura dlya ee issledovaniya [ The luminescence of minerals and apparatus for its investigation 1: Probl. sov. geologiya., 1938, No. 4.

Lozhkin, V. V., Polevoy mineralogicheskiy analiz [Mineralogical field analysis]: ONTI, Moscow, 1937.

Matveyev, K. K. , Ob"yasnitel'naya zapiska po voprosu o titanovykh rudakh $\mathrm{v}$ shlikhakh [Explanatory notes upon the problem of titanium ores in heavy concentrates ]: Trudy. Komiss. syr'ya, vyp. 1.

Nikitin, D. V., Metody poiskovykh i razvedochnykh rabot $\mathrm{v}$ rossypyakh [ Methods of prospecting in alluvial deposits 1: Tsentral'. nauch.-issledov. geol.-razved. inst. 1932, pp. 1-10.

Odinets, Kak vesti shlikhovoye oprobovaniye redkikh mineralov [How to carry out sampling of heavy concentrates for rare minerals ]: Sov. krayevedeniye [Soviet regional studies], 1936, No. 6.

Sasim, P. S., Metodika sbora i obrabotka. shlikhov [Methods of collecting and processing heavy concentrates]: Izd. Zap.-Sib. geol. rasved trudy,Tomsk. 1934.
Sasim, P. S., Metodika sbora shlikhov [ Methods of collecting heavy minerals: Razvedka nedra., 1936, No. 17.

Serdyuchenko, D. P. , Otkrytiye olova na Severnom Kavkaze v svyazi s mineralogo-khimicheskim izucheniyem shlikhov [ The discovery of tin in north Caucasus in connection with mineralogical-chemical studies of heavy minerals]: Uchen. zap. Rostov-Donsk. univ., 1935, vyp. 3.

Sigov, A. P. , Promyvka shlikhov pri geologo-razvedochnykh rabotakh [ The washing of heavy minerals during geological-survey operations], Sov. zolotoprom., 1937, No. 3.

Schlikhovye izyskaniya [Heavy-mineral studies]: Trudy nauch. -issledov. inst. Sverdlovsk, 1939, 4, pp. 1-64.

Fersman, A.Ye., Perspektivy rasprostraneniya poleznykh iskopayemkh na territorii Soyuza [Aspects of the distribution of mineral deposits in the Union 1, Akad Nauk, Izd. 1932.

Flerov, B. L., Primeneniye olovometricheskoy s"emki pri poiskakh korennykh mestorozhdeniy olova [ The application of stannometric survey to prospecting for primary tin deposits 1: Redkiye metally, 1935, No. 1.

Khrushchev, N. A., Materialy po izucheniyu poleznykh iskopaemykh severo-vostochnogo Zabaykal'ya [Data from the study of the mineral deposits of northwestern Transbaikall: Gl. geol.-razved, upr., 1931, vyp. 90.

Chuyeva, M. N., Shlikhovoy analiz [Heavy mineral analysis 1: Tsentral'. nauch. -issledov. geol.razved. inst., Izd. 1937.

Shakhov, F. N. Poiski mestorozhdeniy redkikh metallov v Sibiri [Exploration for deposits of rare minerals in Siberia]: Zap. -Sib. geol. trudy, Izd. , Novosibirsk 1937.

The Necessary Instruments and Reagnets for Field Work

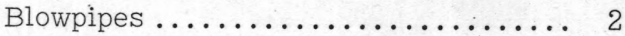

Platinum wire ................. 3

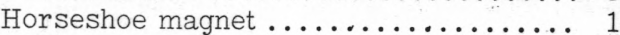

Scale of hardness ................. 1

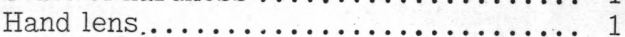

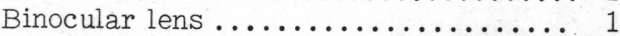

Collection sieve .................

Alcohol lamp .........................

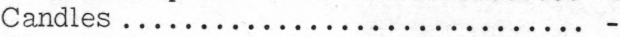

Brushes (assorted sizes) $\ldots \ldots \ldots \ldots \ldots \ldots$

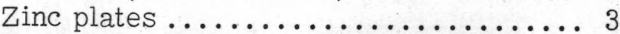

Porcelain plates ................. 3

Gypsum plates ....................... 3

Microscope slides ............... 1 carton

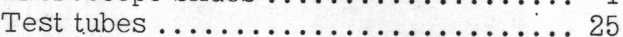

Capillary tubes $\ldots \ldots \ldots \ldots \ldots \ldots \ldots \ldots$ -

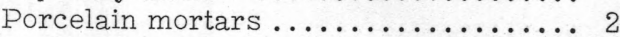

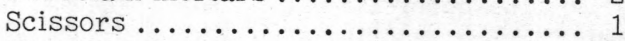

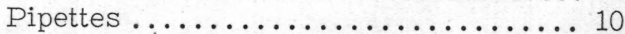

Hammer with anvil ............... 1
Watch glasses .................. 10

Pocket knife ................... 1

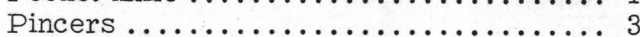

Scale with weights ............... 1

Chemical glasses ................. 10

Medium-sized funnels ................. 5

Potassium nitrate ............... $100 \mathrm{~g}$

Nitric Acid .................... $500 \mathrm{~g}$

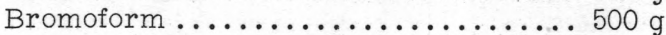

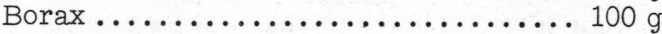

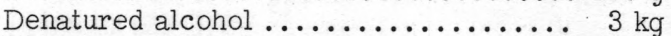

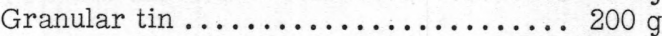

Ammonium molybdate .............. 100 g

Hydrogen peroxide............... $200 \mathrm{~g}$

Hydrochloric acid ............... $500 \mathrm{~g}$

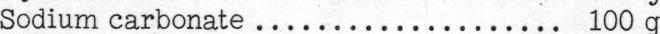

Sulfuric acid .................. $500 \mathrm{~g}$

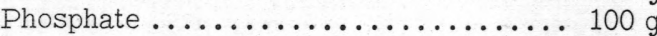

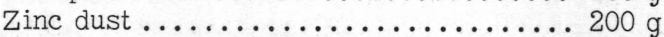




\section{SPECTROSCOPIC METHODS}

By S. A. Borovik.

Spectroscopic analysis is important for determination of valuable metals. Gallium, indium, germanium, and rhenium are usually found in concentrations measurable only by the spectroscope. Spectroscopic analysis, also, has a large number of advantages in the determination of other elements.

The work of Gramont, Hartley, Pollock, and lately, Gerlach Scheibe, and Mannkopff, has brought quantitative spectroscopic analysis to an accuracy closely approaching that of the best chemical methods and exceeding them in sensitivity.

The chief advantage of spectroscopic analysis is the speed by which results are attained. Under favorable conditions an accurate quantitative analysis of an unknown sample may be made in 5 to 10 minutes. This is especially valuable in geochemical surveys because it enables the number of analyses to be increased ten to twenty times. The field work done by the spectroscopic laboratory in Khapcheranga and in Khalilov confirms this statement.

Recently, the State optical institute constructed a special type of spectrograph to be used in the field. This spectrograph is a small instrument of the self- collimating type; a diagram of the instrument is given in Figure 52.

In the field spectrograph the light from the arc (1), where the sample is placed falls on the slit (2) and then reaches the quartz prism (3). It is reflected at right angles and falls on a quartz lens (4). After passing through the lens, the light falls in a parallel beam on the sylvite prism (5), is reflected from the silvered top, and returns through the same lens (4). Passing through the prism (3) the beam of light forms the image of the spectrum in the focal plane (6) of the optical system where the photographic film is placed. A diagram of the electric arc circuit is shown in Figure 53. An overall view of the instrument is given in Figure 54 .

This apparatus was used chiefly for determining $t$ in. Prokof'yev and Islamov have developed a method which they call "the method of the emergence of line." A sample is ground to 200 mesh and placed in a carbon electrode with a cup $2 \mathrm{~mm}$ in diameter and 4 to $5 \mathrm{~mm}$ deep. This electrode serves as an anode and is placed at the bottom. Another carbon rod with a cone-shaped tip is fastened above and serves as the cathode. The authors who devised this method give the following table for finding the concentration of tin (Table 12).

Table 12. --Spectral lines used for quantitative analysis of tin

\begin{tabular}{|c|c|}
\hline Tin concentration (percent) & Lines and their characteristics \\
\hline $\begin{array}{l}\text { Considerably less than } 0.05 \text { (order of } \\
\text { magnitude of thousandths of a percent) }\end{array}$ & $\begin{array}{l}\text { The line } 2429.5 \text { is present. In comparison with } \\
\text { the lines of the surrounding structure, it is } \\
\text { weaker in its intensity. }\end{array}$ \\
\hline $\begin{array}{l}\text { Less than } 0.05 \text { (order of magnitude of } \\
\text { hundredths of a percent) }\end{array}$ & $\begin{array}{l}\text { The line } 2429.5 \text { is present. In its intensity it } \\
\text { does not differ from the lines of the band } \\
\text { structure. }\end{array}$ \\
\hline 0.05 & $\begin{array}{l}\text { The line } 2429.5 \text { is clearly visible, weak lines } \\
\text { of } 2546.5,2421.7 \text { and } 2317.2 \text { are slightly } \\
\text { visible. }\end{array}$ \\
\hline $0.1 \ldots$ & $\begin{array}{l}\text { Line } 2421.7 \text { is clearly visible, weak lines } 2571.6 \\
\text { and } 2334.8 \text { as well as a slight image of line } \\
2786.0 \text { are visible. }\end{array}$ \\
\hline $0.2 \ldots$ & A scarcely noticeable line 3032.8 is visible \\
\hline $0.3 \ldots$ & $\begin{array}{l}\text { Line } 3032.8 \text { becomes more visible. Very slight } \\
\text { images of lines } 2317.2,2913.5 \text { and } 2408.2 \\
\text { become visible. Lines } 2594.4 \text { and } 2850.6 \text { are } \\
\text { very clearly.seen. }\end{array}$ \\
\hline $1.0 \ldots$ & $\begin{array}{l}\text { A suggestion of line } 2813.6 \text { is visible. Lines } \\
2408.2,2913.5 \text { are weak but clearly seen. }\end{array}$ \\
\hline $3.0 \ldots$ & $\begin{array}{l}\text { Very weak lines } 2331 \text { appear. Juine } 2455.9 \\
\text { becomes much more distinct in comparison } \\
\text { with the intensity of the nearest line of the band } \\
\text { structure. }\end{array}$ \\
\hline $10.0 \cdots$ & $\begin{array}{l}\text { Line } 2408 \text { becomes clear. Very weak line } 2268 \\
\text { and weak line } 2558.0 \text { appear. }\end{array}$ \\
\hline
\end{tabular}


Experience shows that this table may be used for determining tin in samples of widely different compositions. This is done by adhering strictly to the same conditions of exposure, development, and sensitivity of plates that were used in preparing this table.

The sensitivity of the perforated negative film for the F. E. D. [sic] Isopanchrome is 700. Eight ampers were supplied to the arc; the exposure time was 60 seconds. Carbon rods of the make "Extra" which have a diameter of $10 \mathrm{~mm}$ were used.

When starting one should check on the working conditions to see how they affect the relation between the emergence of the line and the concentration of tin. Samples were made up with known tin concentrations and spectrographed. If a discrepancy was noticed; the necessary corrections were made in the table. Consequently; the consecutive emergence of the lines remains the same.

However, a complete separation of lines is not obtained with the field spectrograph of the National Optical Institute (GOI). If elements other than tin have to be determined, then the Hilger spectrograph is better, especially the large model. If that one is not obtainable a medium-size model can be used. In Table 13 we list elements which can be detected with these spectrographs.

The sensitivity for most of the elements listed is 0.001-0.01 percent. A sensitivity of 0.0001 percent can be obtained for $\mathrm{Cu}, \mathrm{Ca}, \mathrm{Sr}, \mathrm{Ba}, \mathrm{Mg}, \mathrm{Al}$, and $\mathrm{Ag}$.
However, P, As, Te, B and C are sensitive to only 0.1 percent and can be determined only in copper electrodes. The carbons should be purified by roasting them with a current density of 20 amperes per square millimeter.

These methods require 220 or 110 volts and 8 to 12 amperes, which limits their use under field conditions.

Lundegardh has worked out a method which does not require an electric current; it uses an oxyacetylene flame. Figure 55 shows the device used by Lundegardh. The sample is dissolved ( 3 to $10 \mathrm{ml}$ ) and then vaporized by a stream of air. The vapor is passed through a nipple and mixed with the oxyacetylene in a glass tube before entering the burner. The burner has a quartz tip and a platinum screen to keep the flame from backfiring. The flame is placed directly before the quartz slit of the spectrograph.

By means of this method the following elements can be detected: $\mathrm{Ag}, \mathrm{Au}, \mathrm{Ba}, \mathrm{Ca}, \mathrm{Cd}, \mathrm{Co}, \mathrm{Cr}, \mathrm{Cs}$, $\mathrm{Cu}, \mathrm{Fe}, \mathrm{Hg}, \mathrm{K}$, Li, Mg, Mn, Na, Ni, Pb, Pd, Rb, $\mathrm{Ru}, \mathrm{Sr}, \mathrm{Tl}$.

The sensitivity of the flame spectroscope is considerably less than the electric arc.

When a high-temperature oxyacetylene or oxyhydrogen flame is used, one is able to obtain spectrograms of minerals by placing a powder of the mineral, wrapped in ash-free filter paper (Ramedge) in the flame.

Table 13.--Wave lengths of elements detected in the carbon arc

\begin{tabular}{|c|c|c|c|}
\hline Element & $\begin{array}{l}\text { Wave length of the most } \\
\text { sensitive lines in } A^{\circ}\end{array}$ & Element & $\begin{array}{l}\text { Wave length of the most } \\
\text { sensitive lines in } A\end{array}$ \\
\hline & & & . \\
\hline Ag -.- & $3382.9 ; 3280.7$ & Mo --- & 3798. $3 ; 38664.1 ; 3132.6$ \\
\hline Al -.- & $3961.5 ; 3944.0 ; 3092.7 ; 3982.2$ & $\mathrm{Na}---$ & $3302.3 ; 5890.0 ; 5895.9$ \\
\hline As --- & $2349.8 ; 2288.1 ; 2789.2 ; 2860.5$ & $\mathrm{Nb}---$ & $4059.0 ; 4079 ; 3580 ; 4101$ \\
\hline $\mathrm{Au}-.-$ & $2676.0 ; 2428.0$ & $\mathrm{Ni}-.-$ & $3524.5 ; 3414.8 ; 3619.4 ; 3050.8$ \\
\hline$B-\cdots$ & $2497.7 ; 2496.8$ & Os --- & $2909.1 ; 3058.7 ; 3301.6$ \\
\hline $\mathrm{Ba}---$ & $4554.0 ; 4934.1 ; 5535.5$ & $P=-$ & $2535.6 ; 2553.3 ; 2534.0 ; 2554.9$ \\
\hline $\mathrm{Be}---$ & $2348.6 ; 3130.4$ & $\mathrm{~Pb}-.-$ & $4057.8 ; 3683.5 ; 2833.1$ \\
\hline $\mathrm{Bi}$ & $\begin{array}{l}\text { 3067. 7; 2898.0; 2938. 3; 2989.0; } \\
\quad 3024.6\end{array}$ & $\begin{array}{l}\mathrm{Pd}--- \\
\mathrm{P}---\end{array}$ & $\begin{array}{l}\text { 3404. 6; 3634. 7; 3609. } 6 \\
\text { 3064. 7; 2659. 4; 2998.0 }\end{array}$ \\
\hline C & 2478.6 & $\mathrm{Ra}-$. & 3814.4 \\
\hline $\mathrm{Ca}---$ & $4226.7 ; 3933.7 ; 3968.5$ & $\mathrm{Rb}---$ & $4201.8 ; 4215.6 ; 7800.3 ; 7947.6$ \\
\hline $\mathrm{Cd}---$ & $\begin{array}{l}2288.0 ; 3261.1 ; 3610.5 ; 2265.0 ; \\
\quad 2144.4\end{array}$ & $\begin{array}{l}\text { Re }--- \\
\text { Rh }---\end{array}$ & $\begin{array}{l}3460.5 ; 3464.7 ; 3451.9 \\
3434.2 ; 3692.4\end{array}$ \\
\hline $\mathrm{Ce}---$ & $\begin{array}{l}3801.5 ; 4186.6 ; 3560.8 ; 4133.8 \\
\quad 4137.6\end{array}$ & $\begin{array}{l}\mathrm{Ru}--- \\
\mathrm{Sb}---\end{array}$ & $\begin{array}{l}3728.0 ; 3799.3 ; 3499.0 ; 3436.7 \\
2598.1 ; 2528.5 ; 2877.9\end{array}$ \\
\hline Co --- & $3453.5 ; 3405.1 ; 3502.3 ; 3412.3$ & Se --- & $3613.8 ; 3630.8 ; 3572.6$ \\
\hline $\mathrm{Cr}---$ & $3578.7 ; 3593.5 ; 3605.3 ; 4254$ & Si --- & $2881.6 ; 2516.1 ; 2506.9$ \\
\hline Cs -.- & $4555.3 ; 4593.2$ & Sn --- & $3175 ; 2840 ; 3034$ \\
\hline $\mathrm{Cu}---$ & $3247.5 ; 3274.0$ & $\mathrm{Sr}---$ & $4077.7 ; 4215.5 ; 4607.3$ \\
\hline Fe --- & $3581.2 ; 3719.9 ; 2483.3 ; 3020.6$ & $\mathrm{Ta}---$ & 2714. $7 ; 2653.3 ; 2647.5$ \\
\hline $\mathrm{Ga}-.-$ & $4172.1 ; 4033.0 ; 2943.6 ; 2874.2$ & Te -.- & $2385.8 ; 2383.3$ \\
\hline $\mathrm{Ge}=--$ & $2651.2 ; 3039.1 ; 2754.6$ & Th --- & 2837. $3 ; 3741.2 ; 4019.1$ \\
\hline $\mathrm{Hg}---$ & $2536.5 ; 3650.2$ & $\mathrm{Ti}---$ & $3349.4 ; 3361.2 ; 3234.5$ \\
\hline in -.- & $4511.3 ; 4101.8 ; 3256.1 ; 3039.4$ & Tl - - & $3775.7 ; 3519.2 ; 2767.9$ \\
\hline Ir - - - & $3220.8 ; 2924.8 ; 3133.3 ; 2849.7$ & $V \quad--$ & $3184.0 ; 3185.4 ; 4118 ; 3093.1$ \\
\hline $\mathrm{K}--$ & $4044.2 ; 4047.2$ & W - - & $2944.4 ; 2947.0 ; 4008.8$ \\
\hline Li - - & $4603.2 ; 3232.7 ; 4132$ & $\mathrm{Y}---$ & $3710.33600 .7 ; 3774.3$ \\
\hline $\mathrm{Mg}$ & $2852.1 ; 2795.5 ; 2802.7$ & Zn -.- & $2138.5 ; 3345.0 ; 3302.6$ \\
\hline $\mathrm{Mn}---$ & $2794.8 ; 2798.3 ; 2801.1 ; 4030.8$ & $\mathrm{Zr}---$ & $3392.0 ; 3438.2 ; 3496.2$ \\
\hline
\end{tabular}


This method requires, of course, two steel cylinders equipped with reducing valves to contain the oxygen and acetylene or hydrogen. The lines of those elements which are most easily excited, such as Rb, Cs, $\mathrm{Ca}, \mathrm{Sr}, \mathrm{Ba}$, In, $\mathrm{Tl}$, Li, $\mathrm{Na}$ and $\mathrm{K}$, may be observed in the flame of a Bartel-type gasoline lamp.

Placing the mineral sample directly into the oxyacetylene or the oxyhydrogen flame usually fails to produce a spectrum. If the easily excited elements listed above are present in the sample, they should be changed into compounds that vaporize easily. A small amount of the sample is powdered and mixed with hydrochloric acid. A fine bent platinum wire is dipped in the resulting solution and placed in the flame. Since the spectrum is very simple, a visual examination by means of a hand spectroscope is sufficient. Preliminary experiments with pure'salts of known elements should be helpful in learning to recognize the lines of these elements from their colors and positions. Yellow lines in such a flame are usually the well-known line of sodium, $5890 \AA$; red lines are: $\mathrm{Li} 6708 \mathrm{~A}$, which is closer to the yellow $\mathrm{Na}$ line, and K 7668 A, situated further away. If the spectroscope has a scale, then one is able to record the scale divisions at which the lines appear, but even in a simple spectroscope without a scale, it is easy to estimate the positions of these lines. The blue line of indium, $4511 \AA$ is very characteristic, but this 0 line is easily confused with Cs $4555 \mathrm{~A}$; and Sr $4607 \mathrm{~A}$; in this case it is difficult to get along without the scale. The green lines Tl $5351 \mathrm{~A}$ and Ba 5536 A are more easily detectable. Rubidium gives a violet line $4202 \AA$.

An auxiliary prism fastened before the slit is very helpful. (The spectroscopes which are manufactured by the Optical-mechanics plant no. 5, are equipped with such prisms.) By placing a second burner at the side, two spectrums may be obtained simultaneously, one above the other. By putting the unknown sample in the flame of one burner, and a known salt or a mixture of salts into the other burner, one can determine without error what elements are contained in the sample. The following procedure is recommended for the gasoline burner: The powder of the unknown sample is placed in a crucible containing hydrochloric acid and metallic zinc. The crucible is then placed next to the cup which serves to kindle the burner. Spray from the solution resulting from the generation of hydrogen will be drawn into the flame of the burner, and clear spectral lines can be observed.

The data of spectroscopic analysis were in many cases useful in the determination of minerals. Compared with chemical analysis, spectroscopic analysis is cheaper and quicker. At the present time, spectroscopic analyses for tin in 2000 samples can be accomplished in 20 days at a cost of 5000 rubles; tin determinations by chemical methods would require 10 months' work by two expert analytical chemists and cost 50,000 rubles. Analyses for indium in 1000 samples, which were carried out in the spectral laboratory of the Lomonosov Institute, required a total of two months' work. It would take an expert chemist approximately 20 years to perform these analyses. 6/

${ }^{8}$ In recent years the $\mathrm{X}$-ray spectroscope has also gained in popularity. Owing to its complicated make-up, however, it cannot be used in the field. See literature: Borovsky, I. B., Present status of the X-ray spectroscope See literature: Borovsky, I. B., Present status of the X-ray spectroscope
abroad. Akad. Nauk, SSSR, Trudy Lomonosovsk. inst., 1937, tom 9, abroad. Akad. Nauk, SSSR, Trudy Lomonosovsk. inst., 1937, tom 9,
pp. 209-245 (standard literature); Borovsky, I. B. and Blokhin, M. A., X-ray pp. 209-245 (standard literature); Borovsky,
spectral analysis, GONTI, 1939, pp. 1-493.

\section{Bibliography}

Borovik, S. A. and Filippov, A. N., Spektral'nyy analiz. Sovremennye fiziko-khimicheskiye metody khimicheskogo analiza [Spectral analysis. Modern physicochemical methods of chemical analysis], Vyp. 1., Goskhimtekhizdat, Leningrad, 1932.

Gerlach, W. and W., Spectrokhimicheskii emissionnyi analiz [Spectrochemical emission analysis] (translated from German under the direction of S. A. Borovik), ONTI-Khimteoret., Leningrad, 1936.

Ozerov, I. M., Stannometricheskaya s"yemka kak poiskovyy metod [Stannometric survey as a prospecting method]: Razvedka nedr., 1937, No. 24, pp . 52-56.

Tolmachev, Yu. M., Primeneniye spektral'nogo analiza pri geologopoiskovykh rabotakh [The application of spectrum analysis to geological prospecting operations]: Priroda, 1936, no. 1, pp. 28-31.

Schheibe, Gunter, Khimicheskiy spectral'nyy analiz [Chemical spectrum analysis] ONTI-Khimteoret., Leningrad, 1938.

Strock, L. W. Spectrum analysis with the carbon arc cathode layer: 56 pp. London, 1936.

\section{Examples}

Exploration for tin: The Academy of Science is publishing "A practical guide for tin prospecting by means of the spectroscopic method." B. L. Flerov (1938) describes the use of spectroscopic methods in prospecting as follows:

"The spectrometallometric survey is being used more of late. Compared to panning, this method has these advantages: 1) it is useful in studying all types of mineral deposits; 2) it is more reliable, because the spectrograph makes possible the detection of powdered cassiterite, which is usually lost during panning, and of cassiterite-bearing rock; 3) the samples do not have to be carried far, and it is possible to work in the absence of water; 4) the tin content of the samples may be determined rapidly; 5) many analyses may be performed at low cost; and 6) samples may be taken from deep drill holes.

"On the other hand, the spectrograph is several tens of times less sensitive than panning which easily exposes $20 \mathrm{mg}$ of cassiterite in the pan (0.0002 percent). Parts of the sample are lost when using the spectrometer. Besides, panning requires only the most primitive devices, whereas spectrometry requires an electric current and a spectrograph. The chief disadvantage of a stannometric survey using the panning method is that it cannot be applied to sulfide mineral deposits having micro-occurrences of cassiterite; however, there are many sulfide deposits containing grains larger than $0.05 \mathrm{~mm}$, which can be captixred with a pan."

The author (B. L. Flerov) warns against excessive enthusiasm for the spectrograph, whose application may be limited to: sulfide and other deposits with micro-occurrences of tin; mineral deposits with layer of detritus too deep for easy drilling; large surveys which are economical of 
electric power and involve a great number. of samples of deluvium and ore which can be given a preliminary analysis on the spot; areas where water is absent. Small survey parties working on mineral deposits containing cassiterite coarscr than $0.2-0.5 \mathrm{~mm}$ may make a stannometric survey by planning.

\section{Comment (A. Fersman)}

Spectroscopic methods may also be applied to the qualitative determination of minerals which contain rare earths. Some rare earths give absorption lines when the mineral is examined in bright sunlight through a small hand spectroscope (direct-vision). These absorption lines are very well displayed by apatite and monazite and permit one to distinguish apatite from beryl and monazite from garnet.

\section{FLUORESCENT METHODS}

By A. F. Sosedko with a supplement by A. Ye. Fersman

Lately, the fluorescence of minerals under the action of cathode, ultraviolet, and other short waves has been successfully used in prospecting. At present there are over 400 known varieties of fluorescent minerals which have different colors of fluorescence, and which fluoresce to different degrees depending on the deposits from which they were obtained. Fluorescence is probably the effect of a disturbance in the equilibrium of the crystal lattice caused by mechanical rupture, or by the presence of extraneous atoms or ions in the lattice spaces. Each local disturbance of the electrostatic equilibrium facilitates the temporary transition of the lattice to a higher energy level, which on falling causes the emission of visible light.

Unfortunately, there has been rio research into this problem and the principles for a classification of minerals according to their fluorescence is not at hand. Scheelite, which is difficult to distinguish from quartz, usually gives a very intense fluorescence of a lovely light blue color. However, there are varieties (sometimes from the same deposit) which are distinguished by a green color, and specimens of scheelite are found which do not react at all under cathode and ultraviolet rays. Similarly, some diamonds will not fluoresce, although many do.

The fluorescence of a substance under ultraviolet or cathade rays is caused by changes which occur within the molecule, the atom, or the lattice when bombarded by the rays. To become fluorescent a substance often requires the presence of a small number of extraneous molecules or atoms. These extraneous substances or "activators" are either tied to the original lattice by means of valence bonds or are present in the form of neutral atoms that are uniformly spaced within the crystal lattice, deforming and depressing it. In certain cases the activators are atoms of heavy metals, such as the atoms of sodium [sic] in rock salt. Observations on artificially prepared fluorescent compounds have shown that fluorescence is produced by a very small quantity of an activator, and that fluorescence reaches a maximum for a definite optimum quantity. In zinc sulphide the optimum concentration of the activator, copper, is 1 in 10,000. In some cases fluorescence is produced by such a negligible. amount of activator that the activator cannot be detected. Different activators occurring in the same substance act upon one another to change the color of fluorescence or to extinguish it. The fluorescence produced by copper is extinguished by bismuth. Spectroscopic analysis shows that a different type of fluorescence is obtained where rare earth, chromium and nickel salts are present. Here the fluorescent radiation is apparently produced by rare earth, chromium or nickel ions which have been isomorphically substituted in the crystal lattice. Line spectrum obtained during fluorescence is caused by the activator ions rather than the mineral itself. Of the rare earths, samarium gives a reddish hue; praseodymium, red and green; ytterbium, an excellent violet; and chromium, red.

There are some substances which are able to fluoresce without the presence of activators because of their lattice structure. These substances include the salts of the uranyl group, $\mathrm{UO}_{2}$.

The fluorescence of a number of minerals, such as the carbonates, may vary from deposit to deposit. Conditions prevailing during depositions may determine the character of fluorescence by influencing the lattice structure of minerals.

Ultraviolet rays, cathode rays, and $\mathrm{X}$-rays may be used in examining minerals.

Sources of ultraviolet rays are the mercuryquartz lamp and the spark discharger. The mercuryquartz lamp is rich in ultraviolet rays in the range 4000 to $2300 \AA$. The mercury-quartz lamp also emits visible light. All visible light, except the violet portion, should be eliminated by a quartz glass filter tinted with nickel salts. This filter is transparent to the visible violet rays and to the ultraviolet rays in the range 2900 to $4000 \AA$.

There are a number of minerals that do not fluoresce under the mercury-vapor lamp, but do fluoresce under shorter ultraviolet rays. Shorter ultraviolet rays are produced by a spark discharge between aluminum or iron electrodes. A semiportable spark unit operating from a regular lighting circuit has been constructed. A portable unit is also obtainable. The semiportable unit uses a high voltage transformer. The spark electrodes are placed in a tube equipped with a handle. This enables one to use the tube like a searchlight, pointing it in the desired direction. The source of current for the portable unit is a magneto driven by a crank and gear system. The magneto weighs from 10 to 12 kilograms and can be carried by one person.

A filter is not used with a spark-discharge outfit because it stops the short ultraviolet rays as well as the visible rays. The fluorescent light must be observed either mixed with ordinary visible light, or by means of a quartz monochromator. Ultraviolet rays may be intensified to detect weakly fluorescent minerals by using a quartz condensing lens. The minerals are placed at the focal point.

Many minerals fluoresce strongly under cathode rays when in a vacuum. Cathode tubes with either cold or hot cathodes may be used, although 
tubes with cold cathodes are safer and require a vacuum of only $0.01-0.001 \mathrm{~mm}$ of mercury.

A cathode tube with cold cathodes usually consists of a closed chamber containing an aluminum cathode in the form of a disk; the anode consists of any material. The anode serves as a support for the mineral to be examined. The vacuum in the tube is adjusted and power amounting to 5 to 15 kilowatts is applied. It takes from 1 to 2 minutes to prepare a sample for examination. Field equipment has also been constructed for cathode ray examinations.

The successful use of ultraviolet rays to detect scheelite rapidly even in minute grains has established the use of ultraviolet rays in identifying a number of minerals. However, the accumulated evidence shows that a specific mineral may fluoresce different colors or, in some instances, not fluoresce at all. It is often impossible to determine the identity of the fluorescing mineral. These circumstances have caused considerable indifference to the use of fluorescent analysis in mineralogy, almost to the extent of its being entirely neglected. However, there is little doubt that despite certain limitations, fluorescent analysis is of great importance and is a necessary method not only for the determination of minerals, but for the practical operations of mining and concentrating scheelite.

Fluorescent minerals may be examined under the microscope by exposure to ultraviolet rays as follows: The ultraviolet rays are produced by a spark discharged and then passed through a condensing lens into the monochromator. In the monochromator the ultraviolet rays are separated from the visible light. By means of a quartz tube, which takes the place of a mirror, the rays are passed into the microscope tube. The mineral to be examined is finely powdered and placed on a quartz slide upon the microscope table. The exposure of minerals to cathode rays is feasible if the cathode tube is of such dimensions that it can be placed upon the microscope table. The fluorescence in the vacuum is observed through the glass of the upper part of the tube.

Study of the fluorescence of minerals when exposed to $\mathrm{X}$-rays has not yet received widespread attention; we will omit a description of the X-ray apparatus.

Up to now the fluorescence of minerals has not received a thorough systematic investigation; we have only a few separate unsystematic observations.

The limited use of fluorescent analysis is due to our lack of knowledge of the causes of fluorescence. The type and intensity of fluorescence depend upon the presence of activator substances, which make up part of the traces of impurities in the mineral. Minerals are seldom chemically pure, for they usually contain a great variety of impurities. These impurities either enter the crystal lattice in the form of isomorphous substitutions or are distributed within the lattice as free atoms or molecules. By understanding the different types of mineral fluorescence, we are able to classify minerals in a new way. Impurities in a mineral are frequently determined by the environment of the mineral when it was formed. Assuming that minerals of similar origin contain similar impurities we can conclude that fluorescent analysis may be used successfully in the study of mineral deposits, in bulk assaying of them, and in mineralogic study of geochemical provinces. Geochemical studies should be preceded by a study of the fluorescence of the minerals involved in these problems. When the fluorescent response of different minerals of a given deposit or given province has been determined, then fluorescent analysis may be effectively applied. The minerals in heavy concentrates may then be quantitatively determined, and many phases of ore analysis, such as heavy-mineral analysis, the analysis of mill tailings and the determination of losses in slimes will be speeded up. It may also be used for determining the genesis of minerals, and establishing the part they play in the genesis of ore deposits.

Not all minerals possess the property of fluorescence; metallic and dark-colored minerals do not fluoresce. According to P. P. Pilipenko, fluorescent minerals possess ions crystalline lattices.

Furthermore, not all fluorescent minerals fluoresce when exposed to different sources of radiation. A comparatively small number fluoresce under the action of long ultraviolet waves. They fluoresce somewhat more and generally with far greater intensity under the action of ultraviolet rays from the spark discharger. However, examples are known where minerals radiate under the rays of the mercury lamp, but do not radiate under the rays of the spark discharger.

A greater number of minerals fluoresce under cathode rays than under ultraviolet rays. A few investigators claim that minerals radiate more intensely under cathode rays, but their research shows that minerals radiate a greater range of colors under ultraviolet rays than under cathode rays. Thus, calcite gives light yellow, pink, dark red, and dark purple under ultraviolet rays, whereas under cathode rays it radiates only yellow to fiery yellow colors. Because of this, it is hard to tell which light source is the most suitable. It is important to select the most efficient light source for each mineral.

In studying the fluorescence of minerals it is sometimes necessary to create conditions which will increase the intensity of the fluorescence of the specimen to be examined. In examining minerals under cathode rays it is recommended that a fresh fracture be used. Crushing the mineral to a powder enlarges the surface of exposure and increases the fluorescence. Scratching the mineral with a needle or a knife will increase the intensity of the fluorescence. When using X-rays, however, powdering the mineral will cause the fluorescence to disappear, and the examination should be made with a large fragment of the mineral.

Some colored minerals will fluoresce only if they are ground into a fine powder and examined under a microscope. Sapphire is an example.

Certain minerals like wolframite and molybdenite can be changed into fluorescent compounds by means of a chemical process. This is used when prospecting for them in heavy-mineral studies. 
With fluorescent analysis a quantitative as well as a qualitative determination of fluorescent minerals can be made. Samples are crushed and separated into fractions according to their grain sizes. The grains are then counted under a microscope. A number of methods of making the quantitative calculation have been proposed which we need not discuss. The accuracy of the calculation is sufficient for technical needs. This method gives the following sensitivities for the determination of scheelite:

$\begin{array}{cc}\begin{array}{c}\text { Percent } \\ \text { concentration }\end{array} & \begin{array}{r}\text { Percent } \\ \text { sensitivity }\end{array} \\ 1.8 & 1 \\ 5-10 & 2 \\ 10-20 & 3\end{array}$

The' quantitative determination of fluorescent minerals is being currently applied to scheelite, zinc, and corundum ores. It is especially applicable to scheelite and zircon for which a method has been worked out in detail. Its advantages are rapidity (10-12 minutes for 6 determinations) and a cost many times lower than the average cost of a chemical analysis.

The fluorescent response of characteristic minerals is described below. Scheelite, the carbonates, and fluorite give the most intense fluorescence:

Scheelite (CaWO4).--Scheelite fluoresces very well, but not always under the rays of the mercuryquartz lamp. It fluoresces an intense blue (sometimes green), making it easy to distinguish from the other minerals. Fluorescent analysis is very applicable in prospecting for scheelite, in guiding survey operations, or as a control in the operation of scheelite concentrating equipment.

Carbonates. --Among the stable minerals, calcite and aragonite are especially characteristic because of their sensitivity and variety of colors. With respect to ultraviolet and cathode rays there are two types of calcite. One does not fluoresce when irradiated; the other does. Under ultraviolet rays calcite fluoresces waxy-yellow, pink, or dark red. Under cathode rays the fluorescence is less varied, being yellow and fiery-yellow. P. P. Pilipenko attributes the different colors of calcite's fluorescence to impurities, mainly of manganese and partly of iron. colors.

$$
\text { Fluorite.--Fluoresces intense blue or bluish }
$$

Cryolite.--Does not fluoresce under the ultraviolet rays of the mercury lamp, but under the rays of the spark discharger it gives a weak fluorescence and possesses a clear white phosphorescence. This property is important in prospecting for cryolite in the Il'men mountains and on the Kol'skiy Poluostrov [Kola peninsula 1 .

Corundum. --Different types of corundum fluoresce differently. The red corundum from Yakutsk fluoresces an intense ruby color which is due to inclusions of chorium. Massive sapphires from Semizbugu and from central Asia usually do not fluoresce, but when powdered and examined under the microscope they fluoresce light blue.
Diamond. --Fluoresces with a light blue or yellow green color.

Apatite. --Specimens from different deposits fluoresce different colors, such as pink, violet, green, or yellow.

Zircon.--Fluoresces an intense orange which is easily distinguished from the fluorescence of other minerals.

Data upon the fluorescence of a number of other minerals is given in Table 14.

Conclusion:

Fluorescent analysis frequently makes possible rapid mineral identification and quantitative estimation of the mineral composition of a sample.

The application of fluorescent analysis is complicated by the fact that the same minerals from different deposits may fluoresce differently, and that different minerals may give identical fluorescence.

The type of fluorescence is chiefly determined by tiny amounts of impurities. Thus, minerals formed under the same conditions will contain nearly the same amounts of impurities, and minerals from the same deposit or the same geochemical province will have the same fluorescent properties. In this case fluorescent analysis is extremely valuable in bulk sampling or concentrating.

Fluorescent analysis may be successfully applied in the field.

Though the method of fluorescent analysis is still not perfected, it promises to give valuable and productive results. It should be tested out in every field of mineralogy with the aim of expanding and extending it.

\section{Bibliography}

Bogoslovskiy, M. G. , Savitskaya, P. V. and Solomkin, S. G., Lyuministsiruyushchiye mineraly [Fluorescent minerals $]$ : Sov. geologiya, 1938 , no. 10, pp. 99-110.

Komovskiy, G. and Abolenskiy, F. Lyuministsentsiya mineralov $i$ apparatura dlya yeye issledovaniya [The fluorescence of minerals and apparatus for its investigation]: Probl. sov. geologiya, 1938, no. 4, pp. 332-338.

Komovskiy, G. and Razumnaya, E. G. , Mikroskop s katodnoy yacheykoy i lyuministsentnyy kolichestvennyy analiz [A microscope using cathode rays for qualitative fluorescent analysis]: Sov. geologiya,1938, no. 11 , pp. 111-117.

Savitskaya, P. V. , Lyuministsentnyy analiz shlikhov [Fluorescent analysis of heavy minerals]: Sov. geologiya, 1938, no. 6, p. 123. (The chemical preparation of heavy minerals to determine fluorescent wolframite and molybdenite).

Flint, E. and Bogoslovskiy, M. , Metody katodnoy lyuministsentsii [ The method of cathode fluorescence]: Trudy Vses. inst. min. syr'ya, 1937. (Especially for the analysis of heavy minerals).

Dérib'er'e, M. , Les applications practiques de la luminiscence $\lceil$ The practical application of fluoresence], 275 pp., Paris, 1938. 
Table 14. --Fluorescence of minerals in cathode and ultraviolet rays

\begin{tabular}{|c|c|c|}
\hline Mineral & In cathode rays & In ultraviolet rays \\
\hline Diamond - - - & $\begin{array}{l}\text { azure, dark blue, green. } \\
\text { In the Urals: bluish. }\end{array}$ & azure, violet, yellow-green. \\
\hline Apatite - - - & yellow, pale green, orange, lilac. & pink, violet, red. \\
\hline Barite - & violet, yellow, pink. & violet, yellow, pink. \\
\hline Beryl & violet. & violet. \\
\hline Bauxite - - & violet, cherry. & orange. \\
\hline Gypsum - - & violet. & ---- \\
\hline Diaspore -- - - & light green. & greenish-yellow. \\
\hline Dumortierite - & dark blue. & ---- \\
\hline Calamine - & light blue, light green, light violet. & light yellow. \\
\hline Corundum - - & orange-red, light blue. & dark red. \\
\hline Lovchorrite - - & pale pink, orange. & ---- \\
\hline 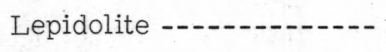 & red. & ---- \\
\hline Molybdenite - & greenish. & ---- \\
\hline Oligioclase - & light green. & violet. \\
\hline Orthoclase - & light blue, dark blue. & yellow. \\
\hline Powellite - & raspberry. & ---- \\
\hline Petalite & light yellow. & yellow. \\
\hline Smithsonite -.-- & pink. & ---- \\
\hline Sphene & light blue. & ---- \\
\hline Topaz & blue, light blue. & greenish-blue. \\
\hline
\end{tabular}

\section{SPECIAL METHODS}

We will deal here with some special methods of prospecting based on phenomena accompanying the oxidation of sulfide ores, such as the secondary migration of solutions and the $\mathrm{rH}$ and $\mathrm{pH}$ of the environment.

Prospecting Based Upon the Study of Oxidation Processes.

Oxidizing sulfide ore bodies have some important diagnostic features (discussed in Chapter V, page 317 ). These features are of such definite character and magnitude that several special geochemical and geophysical methods have been developed for their study.

S. S. Smirnov (1936, especially pp. 123-127), a specialist on oxidation processes, has followed the American practice of analyzing the structure of secondary minerals, especially limonite, occurring as pseudomorphs in different sulfide minerals. A detailed study of the structure of secondary minerals (shape, size, and type of crystal system; porosity, texture, type, and color of limonite) will reveal the identity of the primary mineral (especially, pyrite, chalcopyrite, pyrrhotite). This method may be applied especially to prospecting for copper, and sometimes zinc and lead ores.

Anyone who is interested in gossans is referred to the original treatises.

\section{Prospecting by Thermal Effects}

Oxidizing sulfide minerals give off heat. N. I. Sofronov has suggested that a study should be made of the thermal properties of oxidizing mineral deposits, but there have not yet been experimental applications in prospecting. 
Prospecting by the Chemistry of Secondary $\overline{\text { Processes }}$

The low pH of water in oxidation zones and gossans provides a good prospecting indicator. Another important indicator is a high sulfate ion concentration in the waters. The dispersion halo of the sulfate ion is sometimes quite large and allows one to map areas containing primary sulfides (see page 169).

\section{Prospecting for Salt Deposits on the Basis of Secondary Migration}

Study of borate deposits in western Kazkhstan has led to conclusions important in reconnaissance prospecting work (Nikolayev, 1938). Accumulations of "primary" boron salts are chiefly associated with the final products of crystallization--the potassium salts. During continued weathering the potassium salts are readily washed out, whereas the boron salts are altered, especially in the presence of calcium and magnesium salts, to less soluble compounds. The $\mathrm{R}_{2} \mathrm{O}_{3}$ : $\mathrm{RO}$ ratio drops from 1.67 to 1.5 to 1.25 and lower ( $\mathrm{R}$ represents $\mathrm{Ca}$ and $\mathrm{Mg}$ ).

Prospecting for sedimentary borate should be guided by textures indicating leached potassium minerals. After the borates have been located, potash deposits should be sought at depth or in places protected from water. These results deserve attention and are an excellent example of the application of a thorough analysis of geochemical features to prospecting.

\section{The Use of Redox, or $\mathrm{rH}$ (oxidation-reduction potential)}

Proximity to seepages of petroleum and volatile hydrocarbons may be accurately expressed in terms of changes in $\mathrm{rH}$. Reducing conditions which may be measured accurately increase inversely as the distance from the seepage source. Such investigations have been carried out by the Fuels Institute of the Academy of Sciences along a line of Caucasian mud volcanoes (Gubkin and Fedorov):

"Being closely acquainted with oxidation-reduction conditions in the crater of the mud volcano, we became interested in the problem of why the $\mathrm{rH}$ of the mud breccia (?) at different depths changes in proportion to its distance from the nucleus of the volcano.

"A thorough consideration of the acquired data enables us to deduce the existence of a definite rule here, which may be described in the following manner: Samples of liquid breccia taken from the crater of a mud volcano; in which either in the immediate vicinity or close to it (at distances of not more than one kilometer) there is an indication of petroleum, as a rule show a decrease of $\mathrm{rH}$ with depth, or in other words an increase in reduction intensity ( 9 cases out of 11 ). In a zone of the same radius around volcanoes, which contains no petroleum, $7 /$ this rule was not observed (6 cases out of $8.8 /$ )

\footnotetext{
${ }^{7}$ Asphalt may be present.

The first two exceptions seemed to be due to accidental errors. The last two exceptions are probably not due to accidental errors: It is probable that these volcanoes actually belong in the first category.
}

"As a result of our determinations of $\mathrm{rH}$ in the primary rocks along a line of approach to the volcano we noticed a variation in $\mathrm{rH}$ value depending on whether the area is related to oil deposits of commercial significance, or for small volcanoes not in the immediate vicinity of zones of high oil content. In the first case, we find that the reduction potential in primary rocks was proportional to the nearness of the center of the volcano. This was not only true for rocks of the same formation, but for rocks taken from different formations. In the second case, this tendency was observed only along the trend of a single thin stratigraphic unit, or was not observed at all. These correlations were clearly shown at several places investigated by us (Lok-batan, on the one hand, and the Tyul'ki-tapa and Bulganakskiy volcanoes on the other). For a number of reasons for which we were not responsible, we were unable to check the correlations on the large scale necessary for final proof."

"Thus, these investigations are only of a preliminary nature."

Nevertheless, this method deserves considerable attention. Oxidation-reduction potential will undoubtedly become an important indicator in prospecting for mineral deposits where reduction processes are involved (petroleum, natural gas, asphalt, and to some degree, coal). However, a direct determination of redox intensity is only possible in the liquid and gaseous phases, and is much more difficult in the study of solid substances.

In addition to direct determinations of $\mathrm{rH}$, indirect conclusions as to its approximate value may be made on the basis of studies of stratigraphic sections and their facies changes. For example, a study of the relationships and distribution of ferrous and ferric oxides in marine sediments may lead to conclusions regarding the $\mathrm{rH}$ pattern in the marine basin and even to a method of prospecting. A lowering of $\mathrm{rH}$ inhibits the deposition of $\mathrm{MnO}_{2}$ and leads to the formation of silicate iron ores (chamosite and thuringite). See the work of V. V. Shcherbina (1939) on the paragenesis of sulphur compounds.

\section{The Use of pH Determinations}

Determinations of $\mathrm{pH}$ have not been applied widely to prospecting because of some inherent difficulties. The determination of $\mathrm{pH}$ in waters indicates only the acidity and alkalinity produced by recent geological processes, such as the formation of gossans and weathering. In studies of ancient weathering, data on modern weathering must be used very carefully. Nevertheless, the determination of $\mathrm{pH}$ in studies of contemporary processes furnishes some important information: at low pH (3 to 5) we should expect the precipitation of aluminum silicates as clays; in ore deposits, we should expect the precipitation of the ochers of heavy metals (W, Mo), the formation of free sulfuric acid with the evolution of $\mathrm{CO} 2$ gas on one hand, and the coagulation of $\mathrm{SiO}_{2}$ into opals and semiopals on the other. It is unfortunate that these problems have not been thoroughly studied by geochemists as yet. Only the interesting work of Khitarov (1938) shows the important role of $\mathrm{pH}$ in the migration of metals, such as molybdenum in a supergene environment. Low pH results from two important processes: 
the oxidation of natural sulfur deposits and the oxidation of sulfide deposits. 9/

The migration of the elements is different in regions with high $\mathrm{pH}(9-14)$. In these regions $\mathrm{SiO}_{2}$ is carried off in solution, while $\mathrm{Fe}_{2} \mathrm{O}_{3}, \mathrm{MnO}_{2}$, and sometimes $\mathrm{Al}_{2} \mathrm{O}_{3}$ (at a lower $\mathrm{pH}$ ) are precipitated. In complex ores, Mo and $\mathrm{W}$ are taken up by alkaline solutions. In bituminous deposits, parts of the organic material is extracted (Fersman, 1937, pp. 424-426).

Studies of $\mathrm{pH}$ of acid and alkaline solutions permit us to estimate the $\mathrm{pH}$ of various geological processes on the basis of paleogeographic and geological criteria. For example we know that $\mathrm{pH}$ is a function of the depth zones in marine waters, thus:

Variation in $\mathrm{pH}$ with depth for the South Atlantic Ocean below the tropics

[According to A. V. Kazakov (1938)]

\begin{tabular}{c|c|c|c}
\hline Zone & $\begin{array}{c}\text { Depth in } \\
\text { meters }\end{array}$ & $\begin{array}{c}\text { Temperature in } \\
\text { degrees C. }\end{array}$ & $\mathrm{pH}$ \\
\hline 1 & $0-50$ & 20 & 8.15 \\
2 & $50-500$ & $20-7$ & $8.1-7.7$ \\
3 & $500-1500$ & $7-4$ & $7.7-8.0$ \\
4 & over 1500 & 4 & 8.0 \\
5 & sea floor & about 0.5 & 7.95 \\
\hline
\end{tabular}

Palegeographic data can tell us in which zone a sediment should be classified; a study of the sedimentary basin may determine the probable $\mathrm{pH}$ at which a given rock was formed, and a number of conclusions may be drawn about the accumulation of different minerals. Applying geochemical principles, we may expect the accumulation of phosphorite in zone 2 at the lowest $\mathrm{pH}$, nearly neutral (7.7).

\section{Botanical Methods}

It has long been known that the character of vegetative cover may serve as a prospecting guide. In $1938 \mathrm{~S}$. M. Tkalich pointed out the value of vegetation as an aid in prospecting. Referring to an extensive literature, he listed a special variety of violet, growing on zinc-rich soils (calamine violet), the peculiar growth of certain grasses in areas rich in lead, and the well-known research of Franz Unger in 1836 upon difference in the vegetative cover of siliceous and calcareous soils. These specific peculiarities of the vegetative cover were much emphasized by studies of the mineralogy of the island of Elba in 1909, because there it was entirely clear that the vegetation growing over the serpentines was very different than that over the granites which cut through the serpentines. One does not need to be a botanist to recognize these sharp distinctions.

The idea of using plants as indicators has been repeatedly stressed by investigators in coal districts. Yu. A. Zhemchuzhnikov in a number of cases noted specific types of vegetation cover in regions of outcropping coal deposits. Engineer Ivashkevich, while mapping the Sakhalin coal deposits noticed that areas underlain by Cretaceous rocks were covered by Siberian coniferous forest, whereas the foothills and

\footnotetext{
${ }^{8}$ See the work of Sedletsky regarding this problem. For the relation of clays to $\mathrm{pH}$ see Deribere (1938).
}

valleys underlain by Tertiary coal deposits were covered by a forest of birch, alder and spruce.

A great deal of attention has been paid to the vegetation at the apatite deposits in the tundras of Khibinsk. In valleys where the apatite rocks have undergone weathering, the vegetation is thicker than in valleys where there has been no weathering and concentration of phosphorus. There is also a difference between the lichens growing on bare nephelite rock and on apatite rocks; however, this difference was more of a quantitative than qualitative nature.

In his paper, S. M. Tkalich points out that from the prospector's point of view, plant indicators may be divided into two groups. One group serves as direct indicators, indicating the presence of different substances. For example, saltwort indicates the enrichment of sodium chloride in the soil; Viola zincifera indicates zinc; peat moss indicates peat deposits.

Undoubtedly, biogeochemical methods will yield valuable information about areas containing large quantities of a certain element. Plants rooted in the dispersion halo of a mineral deposit will absorb the corresponding element in increased amounts that can be determined in the plant ash.

Tkalich lists the following four rules with regard to this problem:

If no strict proportion exists between the concentration of a salt in the soil solution and its concentration in the plants, the salt will be enriched in the plants.

Two identical plants, one growing outside a dispersion halo and the other growing within, will contain different concentrations to the same salt even though all other conditions be the same. 
The amount of any element in the ash of a plant may be selective and it is necessary to compare the concentration of this element with that in similar plants from other localities.

The best parts of the plant to use for ash analysis are the plant organs, especially the leaves.

Fifteen years ago S. P. Aleksandrov expressed similar ideas as the result of his studies of radium deposits in south Fergana. He analyzed the ashes of plants growing in the vicinity of a mine and found greater concentrations of vanadium and uranium than he did in plants growing in similar soils in other areas of South Fergana. More recently, analagous methods have been used in Sweden by Brundin and Palmquist, who determined gold, tungsten, molybdenum, tin and other metals in the ashes of leaves. Apparently, their experiments have yielded positive results in the forests of northern Sweden.

These ideas were checked systematically by S. M. Tkalich in the area of the Unashinskarsenopyrite deposits in the Far East. He used the following method:

Several traverses were run across the ore body at distances of 30 to 35 meters from one another. Leaves were collected from plants at regular intervals, with closer spacing in the area of the ore body. The concentration of the element being sought was determined in the ashes of the leaves. In this case the element was iron. The points from which the samples had been taken were marked on a map. Because of the nature of the analysis the average concentrations of the metal compounds were expressed in semiquantitative terms: absent, trace, present, abundant. Points containing similar amounts were contoured, and an interpretation was made concerning the center of dispersion of the known chemical element.

In this case three traverse were laid out, and leaves of beach grass (Calamagrostis) were collected. The ashes of the plants were analyzed for ferric oxide and ferrous oxide. A diagram was obtained which showed a high iron content in ashes of plants growing near the adit on the lower vein, and also near the lower adit on the principal vein. In areas away from the deposit, the iron content was less.

Although attempts to verify the assumptions behind this method have not given very clear results, the method itself is noteworthy.

Plants, according to the data of $V$. I. Vernadskiy and A. P. Vinogradov, very clearly respond to changes in environment. A plant cell behaves as a very accurate indicator, revealing the abundance or deficiency of the different chemical elements; the brilliant research of A. P. Vinogradov in establishing the different biogeochemical provinces has proved that botanical studies may be applied to the solution of many practical problems. Therefore, we must emphasize the importance of biogeochemical research in prospecting, and recommend further research under natural conditions near mineral deposits.

\section{Bibliography}

Déribéré, M., 1938, Application géologiqué de $\mathrm{pH}$ [Geologic application of the $\mathrm{pH}]$ : Soc. géol. France Compte rendu, fasc. 1-2, p. 17.

Fersman, A. Ye., 1937, O velichine $\mathrm{pH}$ v raznykh geokhimicheskikh sistemakh [ The pH of different geochemical systems]: Geokhimiya, v. 3., pp. 424-426.

Gubkin, I. M., and Fedorov, S. F., 1938, Gryazevyye vulkany Sovetskogo Soyuza [ The mud volcanoes of the Soviet Union], Akad. Nauk SSSR, Inst. goryuch. iskop., pp. 33-34.

Nikolayev, A. V., 1938, Fiziko-khimicheskoye izucheniye boratov [ Physicochemical studies of borates], Doklady zapiska.

Shcherbina, V. V., 1939, Okislitel'no-vosstanov. potentsial $\mathrm{v}$ primenenii $\mathrm{k}$ izucheniyu paragenezisa mineralov [Oxidation-reduction potential as applied to the study of the paragenesis of minerals]: Akad. Nauk SSSR Doklady, tom 12, no. 8, pp. 508-510.

Smirnov, S. S., 1936, Zona okisleniya sul'fidnykh mestorozhdeniy [ The oxidation zones of sulfide deposits 1, ONTI.

Tkalich, S. M., 1938, Opyty issledovaniya rasteniy v kachestve indikatorov pri geologicheskikh poiskakh i razvedkakh [Experimental investigation of plants as qualitative indicators of geological prospecting]: Akad. Nauk SSSR, Vestn. Dal'nevost. Filiala, no. 32 , pp. 3-25.

Uspenskiy, Ye., 1925, Zhelezno, kak faktor raspredeleniya vodorosley [Iron as a factor in the distribution of algae], Trudy Botanich. inst. , Moscow.

\section{VISUAL AERIAL-SURVEY METHODS}

The color of rocks and their resistance to weathering stand out in an aerial survey 10/. As shown in Chapter II, both of these features are related to the structure of crystals. The resistance of minerals and rocks to weathering is due to the ability of the crystal lattice to withstand destruction by mechanical, chemical and physiochemical weathering and erosion processes. Petroleum-bearing horizons in Turkmenistan, and also in California, were mapped using the color of rock in sequences containing petroleum. Ores, and especially quartz veins, are very easily mapped by visual studies of aerial photos. Quartz veins are often characterized by their topographic relief and by their extensions over large distances, so that tectonic breaks and even faults may be recognized, especially in regions without vegetation. Ore deposits rich in sulfides stand out by their brown and rust colors, which are easily identified. Outcrops of sulfur, alum, and alunite are distinguished by their white outcrops.

In Canada large veins of ore containing high concentrations of hematite and red dolomite were determined from the air. This led to the discovery of a new vein of pitchblende near Great Bear Lake.

${ }^{10}$ Gaveman, A. V. Aeros"yemka i issledovanie prirodnykh resursov [Aerial survey and the investigation of natural resources], Akad. Nauk SSSR Izd., 1937, 185-233. 
The areas most favorable for prospecting by aerial surveys are the mountain regions about the timberline and the bare tundra.

\section{GEOPHYSICAL METHODS OF PROSPECTING}

It is not my purpose to give a detailed description of geophysical prospecting methods (Sel'skiy, 1938), which have been so widely applied in recent years for mineral prospecting, as a great number of investigations have already been made and practical manuals are obtainable. Each year brings more success in their development, and the sphere of their application is constantly widening, making it possible to map the geology under a thick blanket of alluvium, conglomerate, soil, tundra, sand, or forest.

However, I would like to point out that although -these methods are called "geophysical, " actually they are geochemical methods, since they are based on geochemical, the crystallochemical, and mineralogical properties of ores and their constituents. Therefore, the future progress of the geophysical methods depends not only on technical development and improvements in equipment, but also on detailed studies of different ore bodies.

With the exception of the radioactive method which we will describe later, there are five types of geophysical methods: geothermal, seismic, gravitational, electrical, and magnetic.

The geothermal method is based upon the thermal conductivities of rocks and minerals, and upon the analysis of those processes of the earth's crust which are accompanied by transfer of heat. (See page 215).

The application of this method demands a thorough knowledge of the thermal conductivities of individual minerals and rocks, as well as a geochemical study of thermal processes which accompany different natural reactions. So far there has been insufficient experimental research in this field, and therefore geothermal methods have not been widely used (Kraskovskiy, 1938).

During the past few years seismic prospecting methods have been greatly developed, and there is no doubt that with further improvement, they will yield even more valuable results (Gamburtsen, 1938). These methods are based on stresses produced in rocks by elastic waves. An analysis of these waves yields a general picture of the rock type and structure. Let us note that in granites and crystalline, schists the waves are propagated with a velocity of 4.5 to 6.5 kilometers per second; somewhat lower in limestone (3.5 and 5.5 kilometers per second), [and] lower still in sandstones (1.5-3 kilometers per second).

There is little doubt that the future success of seismic methods depends on an accurate knowledge of the elastic moduli of minerals and rocks (Koridalin, 1938; 1939); these have been studied very little. The mechanical properties of crystalline substances have been neglected in the study of physics of crystals in recent years, even though the future success of seismic methods will depend on the theory of the elastic properties of minerals and rocks.
Gravimetric methods are much more accurate and practical. They are based upon density contrasts, which is of significance in prospecting. Gravimetric methods have a high-instrumental accuracy over a wide range, enabling us to solve a number of geologic and geochemical problems.

The gravitational method permits us to draw definite boundaries between such rocks as gneisses with a specific gravity of 2.6-2.7 and limestones with a specific gravity of 2.8-2.9. This difference of 0.1-0.2 in specific gravity is based upon the chemical composition of the rocks and marks the boundary between two chemical systems.

It is important to apply the gravimetric method wherever a distinct difference in specific gravities exists. This gravity contrast is characteristic of salt deposits and of iron ores. It is possible that gravimetric methods could be applied successfully in prospecting for chromite deposits.

The specific gravities of minerals and rocks have been determined accurately enough to form a basis for the gravitational methods. Of course, the difficulty is that rocks consist of minerals having various specific gravities, which often equalize the sharp contrasts between different rocks and do not permit the determination of results by the gravimetric method.

Magnetic methods are one of the most important geophysical methods. They are based upon the ferromagnetic and diamagnetic properties of mineral deposits.

The extensive application of magnetic methods is due to the accuracy of the instruments and the sharp differences between the magnetic properties of minerals.

A magnetic survey gives clear results even for very small anomalies (100-200 gammas) whereas the magnetic contrast, measured in the same units, for minerals is much greater, and may be expressed in the following manner: magnetic iron 150 thousand gammas, diabase 15 thousand gammas, limonite from 100-500 gammas, alluvial gold up to 300, granites 150-300, and salt 30-40 gammas.

Magnetic methods would be even more successful if magnetic anomalies and the magnetic properties of minerals and rocks were studied in greater detail. Magnetic and ferromagnetic properties are possessed by a special group of chemical elements, located in the middle of the periodic table, and are basically related to the discharging and charging of the electronic shells. The compounds of iron have definite paramagnetic and ferromagnetic properties. This is also true of nickel, cobalt and manganese, to a lesser degree chromium, and the platinum minerals. The study of the magnetic permeability of minerals involves problems of a crystallochemical and geochemical character. Magnetic properties of minerals depend not only on the metals present, but also on the character of the crystal lattice and on the distribution of the metal within it. An increase in magnetism is due to the presence in the crystal lattice of ions of the same element in different valence states. 
The magnetic properties of iron are an excellent example of this. Magnetite consists of a complicated interweaving of ions of ferrous and ferric iron, while in metallic iron we have an unstable interchangeable valence state resulting in zero. Similarly, with cobalt, chromium and manganese, the presence of ions with different numbers of completed electron shells always results in increased paramagnetism. Compounds which contain unstable ions with changeable valences and which are characterized by the presence of free electrons, I have named "berzelides." The investigation of this type of compound is important because paramagnetism in these compounds is accompanied by the absorption of light rays of dark blue or green colors.

The development of magnetic methods demands a study of the magnetic properties of the natural crystal lattices and the relation of these properties to the conditions to their formation.

New and more accurate data will enable us to perfect magnetic methods of prospecting for magnetite, for hematite, and for subsurface alluvial deposits of gold and platinum containing magnetic sediments. Magnetic methods may be applicable in the exploration and study of mineral deposits of bauxite which are associated with ferrous hydrates. Similarly, they could be used in prospecting for manganese ores, which have unstable valences.

A second problem is the study of the magnetic properties of sulfide ores, and in particular, pyrrhotite and some copper ores.

A third problem deals with the investigation of salt deposits, which give negative anomalies due to the diamagnetism of rock salt.

Recently, electrical methods have achieved considerable success and wide application. They involve the study of the electric and electromagnetic fields resulting from both natural and artificial electric currents in the earth's crust.

Many different methods may, be used in electrical prospecting to establish and measure the electromagnetic fields. We recommend study of the conductance and the electromagnetic properties of crystalline substances which have been studied less than the magnetic properties. Electrical methods have not yet been supported by quantitative study of the electrical properties of minerals, especially sulfides, for which these methods are of special interest. The conductivity of the sulfides is closely related to their crystal lattices (which are of the atomic rather than the ionic type), and to the distribution within the lattice of individual atoms of metal and sulfur.

In addition to artificially created electromagnetic fields, there are natural electric currents created by natural chemical reactions, such as the oxidation of sulfides, or contact of bodies of different chemical compositions. All of this indicates that further research and study should be done.

\section{Bibliography}

Gamburtsev, G. A., 1938, Seysmicheskiye metody razvedki [Seismic methods of exploration], ONTI.

Koridalin, Ye. A., 1938, Kora vyvetrivaniya [Zone of weathering ]: Trudy Seysmol. inst., no. 79 . 1939, Izucheniye stroyeniya zemnoy kory seysmicheskimi metodami [ A study of the earth's crust by seismic methods] Akad. Nauk SSSR Izd., pp. 46-73.

Kraskovskiy, S. M., 1938, Obzor glavneyshikh rezul'tatov geotermicheskikh izmereniy [A summary of the most important results of geothermal measurements]: Izv. Geog. obshch., no. 4-5, pp. 612-628.

Sel'skiy, V. A., 1938, Razvitiye prikladnoy geofiziki [The development of applied geophysics]: Trudy Seysmol. inst., no. 79 (9).

\section{RADIOACTIVE METHODS OF PROSPECTING By G. V. Gorshkov}

\section{Introduction}

The radioactive method is based on the difference between the measurable radioactivity of mineral deposits and that of surrounding rocks. The difference may be positive (the radioactivity of the mineral deposit is higher than that of the surrounding rocks), or negative (the radioactivity of the ore mineral is lower than that of the surrounding rocks). Deposits with radioactivities higher than in surrounding rocks are easier to detect than those with lower radioactivities.

If a mineral deposit has a higher or lower radioactivity than surrounding rocks (sedimentary or igneous), it will produce a radioactivity anomaly providing that the other physical properties (ability to emanate, density, porosity, and others) of the rocks and minerals are the same. They must also be free of differences due to meteorological factors, the time of measurement, and the accuracy of measurements.

The majority of mineral deposits, although differing in mineralogical composition, have about the same content of radioactive elements as the country rock. Table 15 gives the average concentrations of radioactive elements in rocks, water, in the air in soil, and in the atmosphere.

This table shows that the radioactivity of the seas and the rivers is about a thousand times less than that of soil. Also, the concentration of radon in the air of the soil is a thousand times greater than its concentration in the atmosphere. The distribution of radon in soil air may be studied by drawing the air directly into an ionization chamber.

The concentrations of radioactive elements given for rocks, soil, and air are averages of many determinations. Single samples may differ considerably in their radioactivity, depending upon their petrochemical composition, location and other factors. A large number of determinations have shown that the radioactivity of acidic rocks is greater 
Table 15.--Concentrations of the radioaztive Elements

\begin{tabular}{l|c|c}
\hline $\begin{array}{c}\text { Description of } \\
\text { environment }\end{array}$ & $\begin{array}{c}\text { Concentration of radio- } \\
\text { active elements of the } \\
\text { uranium series }\end{array}$ & $\begin{array}{c}\text { Concentration of radio- } \\
\text { active elements of the } \\
\text { thorium series }\end{array}$ \\
\hline Soil & $1-2 \times 10^{-12} \mathrm{~g} \mathrm{Ra} / \mathrm{g}$ \\
Sea and river waters & $2 \times 10^{-15} \mathrm{~g} \mathrm{Ra} / \mathrm{cm}^{3}$ & $1-2 \times 10^{-5} \mathrm{~g} \mathrm{Th} / \mathrm{g}$ \\
Soil air & $2 \times 10^{-10}$ curies/1 & $10-8 \mathrm{dto} 10^{-7} \mathrm{~g} \mathrm{Th}^{-\mathrm{cm}^{3}}$ \\
\hline $\begin{array}{l}\text { Atmospheric air } \\
\text { Atmospheric air over the } \\
\text { ocean away from the shores }\end{array}$ & $1-2 \times 10^{-13}$ curies/1 & \\
\hline
\end{tabular}

than that of basic rocks, although the difference is small and both types are within the same order of magnitude.

Up to the present, radioactive methods have been applied only to uranium-radium and thorium ores, and to gases exhibiting radioactivity. However, radioactive methods may be used in prospecting for non-radioactive elements, which are paragenetically associated with radioactive elements that may serve as indicators. The methods can be used in the same manner for studying negative anomalies (prospecting for salt domes).

We will now discuss the most important radioactive field methods.

\section{Emanation Method (Radon and Thoron)}

The emanation method of prospecting for mineral deposits, especially the radioactive ores, is based on the detection of gaseous radioactive emanations in the soil air. At present it is the most basic radioactive method.

Radium and thorium emanations escape into the pores of the country rock, and are found as gases in the soil air where they take part in a gaseous exchange with the atmosphere. This exchange has not been thoroughly studied but it may be shown that decay of radioactive elements causes the emanations entering the atmosphere to be much greater than the emanations returning to the soil. In other words, the process proceeds in one direction.

In homogeneous rocks with a uniform radium content, the concentration of emanation in the rocks is directly proportional to the radioactivity of the rock and cannot exceed the concentrations of thorium and radium required for equilibrium.

Radioactive objects distributed at different depths in the earth's crust will yield emanations in proportion to the concentration of radioactive elements within them. Therefore, the emanation concentration in the soil air will be greatest next to a radioactive object and will constantly decrease with distance from it.

Diffusion usually causes the emanations to be carried away from the emanating object in the direction of decreasing concentration. This problem has not been thoroughly studied from the quantitative point of view. In order to evaluate the emanation method as applied to different rocks, V. I. Baranov and Ye. G. Grachev (1933, 1937, 1938), A. G. Grammakov and N. M. Lyatkovskiy (1933), and A. G. Grammakov (1936) experimented with the method under laboratory conditions; also, G. V. Gorshkov, Ye. G. Grachev, and V. I. Baranov (not published) determined the diffusion coefficients for radium and thorium emanations in different rocks under field conditions. These data are given in table 16.

To give an idea of the depth at which the emanation (radon) method will be effective, materials having different diffusion coefficients are presented in table 17; the distances from the emanating object have been calculated as a function of the diffusion coefficient and as fractions of the initial concentration of the radium emanation of the object.

The values in this table have been computed for emanations from an infinite planar layer. (Grammakov, A. G., Fizicheskie osnovy emanatsionnogo metoda.)

The depth of detection by this emanation method depends upon the magnitude of the diffusion coefficient and the intensity of radioactivity of the radioactive object. The distance or depth is smaller than would be expected from a linear relationship. The depth of detection is several meters in sands, alluvium, and weathered or altered primary rocks. In dense, unaltered primary rocks and in stagnant environments it will be only several tens of centimeters.

The ground water table represents the practical limit of depth. From depths greater than this, radium emanations cannot penetrate to the surface. However, the movement of ground waters may modify the dispersion pattern.

The depth of detection for the thoron emanation method is considerably smaller (on the order of tens of centimeters) than that for the radon method because of the small half-life of thoron. However, the simplicity and dependability of thoron measurements performed on systematically collected samples of soil air, sometimes make the use of the thoron method practical for field work. 
Table 16. --Diffusion coefficients for radium and thorium emanations

\begin{tabular}{|c|c|c|c|}
\hline Type of rock & $\begin{array}{l}\text { Water content } \\
\text { in percent }\end{array}$ & $\begin{array}{l}\text { Diffusion co- } \\
\text { efficient for } \\
\text { radium emanations } \\
\text { in } \mathrm{cm}^{2} / \mathrm{sec} \text {. }\end{array}$ & $\begin{array}{l}\text { Diffusion co- } \\
\text { efficient for } \\
\text { thorium emanations } \\
\text { in } \mathrm{cm}^{2} / \mathrm{sec} \text {. }\end{array}$ \\
\hline Dry quartzitic sand & 0.0 & $6.75 \times 10^{-2}$ & $6.75 \times 10^{-2}$ \\
\hline Moist quartzitic sand & 8.13 & $-\cdots$ & $5.00 \times 10^{-2}$ \\
\hline Same & 10.4 & $-\cdots$ & $3.75 \times 10^{-2}$ \\
\hline Same & 14.2 & $-\cdots$ & $1.75 \times 10^{-2}$ \\
\hline Same & 15.2 & $-\cdots$ & $1.00 \times 10^{-2}$ \\
\hline Clayey sand & dry & $3.5 \times 10^{-2}$ & $-\cdots$ \\
\hline Powdered clay & dry & ---- & $5 \times 10^{-2}$ \\
\hline $\begin{array}{l}\text { Mixture of clayey soil and } \\
\text { quartz sand }\end{array}$ & dry & --- & $3.5 \times 10^{-2}$ \\
\hline $\begin{array}{l}\text { Tabosharskiy alluvium in } \\
\text { summer months in natural } \\
\text { conditions }\end{array}$ & $\begin{array}{l}\text { slightly } \\
\text { moist }\end{array}$ & $7 \times 10-2$ & $-\cdots$ \\
\hline $\begin{array}{l}\text { Altered and disintegrated } \\
\text { Tabosharskiy granodiorite } \\
\text { in natural conditions during } \\
\text { the fall. }\end{array}$ & $\begin{array}{l}\text { slightly } \\
\text { moist }\end{array}$ & $\begin{array}{l}\text { about } \\
0.5 \times 10^{-2}\end{array}$ & --- \\
\hline Solid, unaltered granodiorite & dry & $10-4$ & --- \\
\hline Water 1/ & at $18^{\circ} \mathrm{C}$ & $1.15 \times 10^{-5}$ & Approximately of \\
\hline Air 1/ & $-\ldots$ & $0.0-0.1$ & as those for radium \\
\hline
\end{tabular}

Table 17. --Concentrations of radium emanations as a function of the diffusion coefficient and the distance from the source of the emanations

\begin{tabular}{|c|c|c|c|}
\hline \multirow[t]{2}{*}{$\begin{array}{l}\text { Concentration of radium } \\
\text { emanation in terms of } \\
\text { the initial density of } \\
\text { the emanating object }\end{array}$} & \multicolumn{3}{|c|}{$\begin{array}{l}\text { Distance in meters from the emanating object [ to the zone] of the } \\
\text { given radium emanation concentration, for indicated values of the diffusion } \\
\text { coefficient. }\end{array}$} \\
\hline & $\begin{array}{l}1 \times 10-2 \\
\mathrm{~cm}^{2} / \mathrm{sec}\end{array}$ & $\begin{array}{l}4 \times 10^{-2} \\
\mathrm{~cm}^{2} / \mathrm{sec}\end{array}$ & $\begin{array}{l}7 \times 10^{-2} \\
\mathrm{~cm}^{2} / \mathrm{sec}\end{array}$ \\
\hline $\begin{array}{l}1 \\
1 / 2 \\
1 / 10 \\
1 / 100 \\
1 / 1000\end{array}$ & $\begin{array}{l}0 \\
0.48 \\
1.6 \\
3.2 \\
4.8\end{array}$ & $\begin{array}{l}0 \\
0.98 \\
3.2 \\
6.5 \\
9.8\end{array}$ & $\begin{array}{l}0 . \\
1.26 \\
4.2 \\
8.35 \\
12.5\end{array}$ \\
\hline
\end{tabular}


We shall now examine the basic factors contributing to an emanation anomaly, and estimate the minimum concentration of radium required to produce an anomaly over a given ore deposit. The concentration of the emanations may be determined from the following expressions:

$$
\mathrm{N} \frac{\mathrm{a} \mathrm{Ad}}{\mathrm{n}} 10^{3} \text { curies/liter }
$$

where $\boldsymbol{a}$ is the emanation coefficient $11 /, A$ is the concentration of radium in the rock parts of radium per parts of rock), $d$ is the density of the rock, $n$ is the porosity of the rock (Grammakov, A. G., Fizicheskiye osnovy emanatsionnogo metoda).

It can be seen from this expression that the concentration emanation in rock is dependent not only on the concentration of radioactive elements but also on the density, the emanation coefficient and porosity of the rock. The density of rocks does not vary significantly (about twofold in the extreme cases) but the emanation coefficient and the porosity may vary greatly (from a fraction of a percent to several tens of percent). Therefore, it is impossible to determine a general concentration of emanation which would apply to all types of natural occurrences.

Even at the same prospect and in the same type of rock having uniform concentrations of radioactive elements, the concentration of emanation in the soil air may vary owing. to changes in the emanation coefficient and the porosity according to the formula variation up to several tens of times are possible because either the emanation coefficient or the porosity may exhibit up to tenfold variation. Luckily, most rocks with a high porosity also have a high emanation coefficient so that the two tend to compensate one another.

Up to the present the change in emanation concentration as a function of changes in porosity, the emanation coefficient, and density have not been measured. However, on the basis of indirect evidence (across unmineralized tectonic faults) it may be assumed that the emanation concentration may differ from its background value by a factor of ten. Therefore, an emanation anomaly with a tenfold increase above the background concentration does not necessarily indicate the presence of rocks with an increased concentration radioactive elements in them.

Normally the emanation concentration for radium in the soil air at a depth of 0.5 meters fluctuates from $0.8 \times 10^{-10}$ to $5 \times 10^{-10}$ curies per liter. Thus, emanation anomalies with concentrations greater than $5 \times 10^{-9}$ curies per liter are usually related to an increase in the concentration of radioactive elements within the rocks of the given area.

We will give a brief description of emanation profiles, surface surveys, and anomalies. An emanation profile is a graph of the distribution of the emanation concentrations along a traverse (usually perpendicular to the trend of the rocks). The emanation concentrations are determined in soil air sampled at a definite depth (usually depths of 0.5 or 1.0 meters are most practical).

\footnotetext{
${ }^{11}$ Translators' note: "koeffitsient emanirovaniya"; exact English equivalent not known.
}

The direction of the traverse and the separation and depth of the soil air samples is determined from the geology of the area and from the type of vein and its depth (if this is known before beginning the survey). The depth of detection is estimated from the character of the rocks (alluvium, weathered rocks and others).

A metal tube is used to collect the sample of soil air. It is inserted to a definite depth at each sampling location (for example, to a depth of one meter, or down to the layer dividing clays from gravels). The emanation concentration of the sample is recorded in curies per liter or soil air.

The emanation concentration of the soil air over thorium prospects is determined by analyzing a current of soil air.

The results are presented in the form of a graph. The sample points are plotted on the abscissa and the emanation concentrations are plotted on the ordinate. A geologic section is usually drawn beneath the abscissa at the same scale.

A study of emanation profiles shows that fractures (joints, faults, and some veins), pegmatites, uraniumand thorium-bearing deposits, and several other types of veins show increased radioactivity in the soil in the form of maxima upon the profile graph. Sometimes the maxima appear as narrow sharp peaks and sometimes the curve increases gradually giving a broad maximum. The maxima may have many shapes. Often several small maxima may appear at the base of a large one. Groups of fissures or veins may display a group of peaks upon the profile.

Field work is not usually limited to a few widely separated profiles, but the area to be examined is covered by a series of parallel profiles run at constant intervals. This is called an areal emanation survey.

The results of an areal emanation survey are plotted upon a topographic base map of the area. The zones of equal concentration are outlined by interpolating the data and drawing isograds through points of equal concentration.

Obtaining emanation profiles sometimes requires a long period of time, during which the concentrations do not remain constant but are subject to changes due to meterological factors, the time of the year, and others. Because of this, control points are selected during the survey from which samples taken from time to time (daily during mass sampling). Fluctuations in the emanation concentrations of the control points must be taken into account in order to determine the approximate value of the radioactivity of different areas.

The contour interval of the isograds is determined by the fluctuation in the concentrations and by the character and intensity of the radiometric anomaly. In his work on radioactive mineral deposits $L . V$. Komlev has suggested that only one isograd should be used in contouring the anomalies in Central Asia. This would outline those areas of high concentration which are independent of other factors. According to this system, areas of low concentration would be those which are affected by factors other than the concentration of radioactive elements (such as the emanation coefficient, density, and porosity). 
The scale of the sampling grid or the separation between the samples collected on traverse is important in the application of this method. Because of the large variety of conditions under which radioactive elements occur, only very general instructions can be given. Knowledge of the geology of the area is essential if the survey is to be correctly carried out. Theoretically, large zones of high concentration do not require as frequent sampling as small zones. Similarly; extensive deposits do not require as small an interval between traverses as do small lenticular deposits or tabular veins.

Samples should not be collected more than 10 meters apart between detritus, sands, or disintegrated rock (materials in which the emanation method is practical) have a radius of diffusion on the order of several meters.

We conclude that an emanation survey is not a substitute for geologic studies, but when used correctly, can serve as a valuable auxiliary tool, increasing the effectiveness of the geologic studies and reducing the number of prospecting pits or trenches, especially in the areas that lack outcrops $12 /$.

\section{Gamma Method}

Gamma rays produced by radioactive elements have a greater penetrating power than X-rays. However, gamma ray profiles made from surface measurements will indicate the distribution of radioactive elements only to a depth of 30 centimeters. The depth of detection is much less than that of the emanation method, but interfering factors (weather conditions, emanation coefficient, and others) have a smaller effect on the results of a gamma ray survey. Practically all that the gamma ray method records is the concentration of radioactive elements in the rocks surrounding the instrument. Therefore, its use under field conditions is limited to the following types of problems: the association of ore deposits to radioactive rocks; the study of mineral deposits exposed in outcrops and trenches; the study of mineral deposits by means of underground workings and drill holes (gamma-ray well logging); a rough quantitative determination of the radioactivity of hand specimens of ore; a quantitative determination of the radioactivity of country rock from outcrops, drill holes, and underground workings.

The most important application of the gamma method is in studying outcrops during the initial phases of prospecting a mineralized area. A study of the gamma activity of the outcrops is a reliable, accurate, and rapid method of determining areas of high radioactivity, which should be prospected in detail. In areas which are largely covered by detritus or porous, weathered and fractured rocks, it is expedient to determine the areas of high radioactivity by means of the emanation method. However, if both detritus and solid rock are present, the radio active areas should be located by the emanation method where there is detritus, and by the gamma method where there is solid rock.

\footnotetext{
${ }^{12}$ The emanation method has been used successfully in prospecting for pegmatitic veins at Volyn in the Urals. The veins were covered by
} 10 meters of sedimentary rocks in some places. (I. K. Polovko).
A more detailed study of the area of high concentration is accomplished by making a gamma survey along traverses crossing outcrops or in trenches. Under favorable conditions it is best to make a detailed emanation survey. The distance between samples varies from 0.5 to 10 meters depending upon the variation of radioactivity in the rocks. The interval between traverses varies from several meters to tens or hundreds of meters depending upon the geology. As in the emanation survey, the results of the gamma survey are plotted upon a topographic map and the zones of high radioactivity are colored or shaded. ("Normal radioactivity" is the radioactivity of the fresh rock in the given area.) It is determined by gamma ray measurements.

By correcting for cosmic rays and the background of the instrument, the average radioactivity of the uppermost layers of rocks may be approximately determined.' This concentration is expressed in equivalents of $\mathrm{U}_{3} \mathrm{O}_{8}$ or in other units if more convenient.

Measurements of gamma-ray intensity in subsurface workings permits one to determine the zones of high radioactivity and sometimes allows calculation of the radioactivity of the rocks and ores in terms of equivalents of $\mathrm{U}_{3} \mathrm{O}_{8}$.

The gamma-ray instrument in this type of investigation is like a geologist's microscope, preventing him from making mistakes, as it records the radioactivity even where there is no visible thorium or uranium mineralization.

Either an ionization chamber or a Geiger-Müller counter may be used in all of the problems listed above. It is important to note that the time required to make a measurement depends upon the radioactivity of the rock being tested. This time controls the accuracy of the measurements. The time required by the ionization chamber will not be the same as that of the counter. The ionization chamber will take slightly less time to measure rocks containing small amounts of radioactivity and will give highly accurate measurements. A Kolhurst ionization chamber, with a volume of four liters, will take about the same amount of time to measure rocks of normal radioactivity as will a counter, with an effective surface area of $100 \mathrm{sq} . \mathrm{cm}$. Either instrument is accurate to within about 10 percent. The measurement of rocks that are ten times more radioactive than normal is made ten times faster by using a counter instead of an ionization chamber; however, the measurement is only about 50 percent accurate. The ionization chamber may be made very sensitive by using a gas at high pressure (usually argon), and the Geiger-Muller counter is made sensitive by increasing the effective surface area of the counter. (Up to the present no very good field counter has been developed; the Geiger-Muller counter has many imperfections.) The counter has been successfully applied to determine radioactivity in drill holes that penetrate mineral deposits. This is called "gamma well logging", being analogous to electrical well logging.

The counter may be used to determine the equivalents of $\mathrm{U}_{3} \mathrm{O}_{8}$ or $\mathrm{ThO}_{2}$ in radioactive ores. The accuracy of the determination depends upon a 
uniform distribution of radioactive material within the container in which the measurements are made. To avoid large errors, the ore samples are usually placed into standard containers aind measurements are made on different sides of the container. This permits determinations with an average error of about 20 percent to be made.

The gamma method may be used to determine the radioactivity in equivalents of $\mathrm{U}_{3} \mathrm{O}_{8}$ or $\mathrm{ThO}_{2}$ in typical rocks occurring in outcrops, in mine workings, or in drill holes. The data may be analyzed for the purpose of solving geologic problems or for the purpose of prospecting for nonradioactive mineral deposits. This aspect of radioactive methods in general and of the gamma method in particular has not been studied from the practical point of view.

\section{Other Radioactive Methods}

The measurement of alpha radiation in rock has not been widely applied to field work and we will omit a discussion of this method.

The measurement of the radioactivity of rocks in situ by means of beta rays has not been tried.

Indirect.geophysical radioactive methods of prospecting for mineral deposits should be mentioned. The most economical and rapid of these are the aspiration method of prospecting for radioactive minerals, and the method of determining beryllium in ores by means of the nuclear photo effect of beryllium (Baranov, 1926). In the aspiration method a number of radioactive samples (a geologic collection) are placed under a metal bell jar. The air is drawn out by a vacuum pump and pumped into the ionization chamber of an electroscope. The presence of radioactive elements is detected by an increase in the ionization current recorded by the electroscope. In the second method, the amount of beryllium in a sample of ore is determined by the radioactivity produced in silver (or some other indicator) by beryllium photo neutrons which have been showed by paraffin. Research has shown (Baranov, 1926) that by using an ampoule containing $50 \mathrm{mg}$ of radium, the beryllium content of a sample may be determined with an error of only a tenth of a percent.

\section{Bibliography}

Aydarkin, Gorshkov, Grammakov, Zhadin, Kolchina, Novyy sposob opredeleniya berilliya $\mathrm{v}$ rudakh po foto-neytronam (New method for determining beryl in ores by photo-neutrons): being prepared for publication.

Baranov, V. I., 1926, K Teorii aspiratsionnogo poroda dlya issledovaniya geologicheskikh kollektsiy na radioaktivnost' (On the theory of aspiration of rock for examining geological specimens for radioactivity): Vestnik Geologicheskogo Komiteta, 1925g, No. 4, p. 58.

Baranov, V. I., and Gracheva, Ye. G., 1933, K Teorii emanatsionnoy razvedki (On the theory of emanation surveys): Trudy Radiyevogo Inst. 1933, no. 2, pp. 61-66.
Baranov, V. I. and Gracheva, Ye. G., 1937, Trudy Radiyevogo Inst., no. 3, p. 117.

Grammakov, A. G. and Lyatkovskaya, N. M. : Zhurn. geofiziki, 1935,5 p. 290.

Grammakov, A. G., Zhurn. geofiziki, 1936, p. 133.

Grammakov, A. G., Gorshkov, Lyatkovskaya, Schetchik Geygera-Myullera i yego primeneniye $\mathrm{V}$ geologo-pazvedochnom dele (The Geiger-Müller counter and its application to geological problems) will be published in Izv., VGI.

Grammakov, Gorshkov, Lyatkovskaya, Metodika izmereniy radioaktivnosti, gornykh porod schetchikami Geygera-Myullera (Method of measuring the radioactivity of rocks by the Geiger-Muller counter): will be published in Izv. VGI.

Grammakov, A. G., Fizicheskiye osnovy emanatsionnogo metoda (Physical principles of the emanation method): being prepared for publication.

Gracheva, Ye. G., 1938, Vliyaniye struktury i poristosti porody na diffuziyu radioaktivnykh emanatsiy (The effect of structure and porosity of rocks on the diffusion of radioactive emanation): Trudy Gosudarstvennogo Radiyevogo Instituta, Tom 4, pp. 228-244. (See also Trav. inst. état radium (U. S. S. R.) vol. 4, pp. 228-233)

Meyer, Stefan, and Schweidler, Egon, 1927, Radioactivität, B. G. Teubner, Leipzig, 721 pp.

Shpak, V. A.: Akad. Nauk SSSR, Doklady, 1937, 16, No. 2, III.

\section{Appendix}

The development and specialization of radioactive methods has resulted in the determination of the absolute ages of geological formations. An excellent description of this is given in I. Ye. Starik's latest book, "Radioactive Methods of Determining Geological Time": ONTI, Moscow, Leningrad, 1938, pp. $1-176$.

Radioactive methods are important because they can be used to determine the absolute ages as well as the relative ages of individual formations. The determination of the absolute age of a mineral deposit permits us to determine its relation to tectonic processes and to paleogeographic conditions. This enables us to determine the origin of the formations. A determination of the age of minerals of the Khibinsk mountains indicates that it is necessary, while exploring for fissured rocks on the Kol'skiy Poluostrov [Kola Peninsula], to search for tectonic features produced in the Hercynian. The attempt of V. P. Savchenko to determine the age of oolites at the surface is interesting and has practical significance.

Further investigations into the applications of radioactive methods for age determination will be of importance in prospecting in the f uture. 
